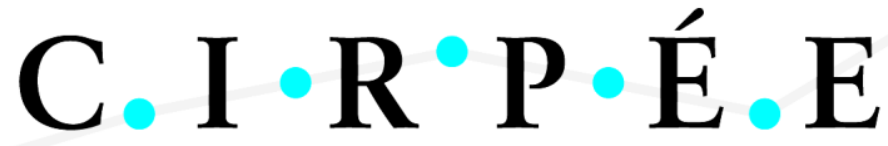

Centre Interuniversitaire sur le Risque, les Politiques Économiques et l'Emploi

Cahier de recherche/Working Paper 13-22

\section{Default and Liquidity Regimes in the Bond Market during the 2002- 2012 Period}

Georges Dionne

Olfa Maalaoui Chun

Août/August 2013

Dionne : HEC Montréal, 3000 Chemin de la Côte-Sainte-Catherine, Montréal, Québec, Canada H3T 2A7. Phone : +514 340-6596; Fax : +514 340-519; and CIRPÉE

georges.dionne@hec.ca

Maalaoui Chun : KAIST, Graduate School of Finance, 87 Hoegiro, Dongdamoongu, Seoul, South Korea, $130-722$.

Phone : +822 958-3424; Fax : +822 958-3180

olfa.maalaoui@gmail.com

Presidential address of Georges Dionne at the Canadian Economics Association Meetings, Montreal, June 1, 2013. Georges Dionne thanks École Polytechnique in France for its hospitality during the writing of different versions of this article. Both authors thank Albert Lee Chun, Mohamed Jabir, and Claire Boisvert for their generous help. Comments from Linda Allen, David Green and an anonymous referee were very useful to improve the previous versions.

Forthcoming at the Canadian Journal of Economics 


\begin{abstract}
:
Using a real-time random regime shift technique, we identify and discuss two different regimes in the dynamics of credit spreads during 2002-2012: a liquidity regime and a default regime. Both regimes contribute to the patterns observed in credit spreads. The liquidity regime seems to explain the predictive power of credit risk on the 2007-2009 NBER recession, whereas the default regime drives the persistence of credit spreads over the same recession. Our results complement the recent dynamic structural models as well as monetary and credit supply effects models by empirically supporting two important patterns in credit spreads: the persistence and the predictive ability toward economic downturns.
\end{abstract}

Keywords: Credit spread, credit default swaps, real-time regime detection, market risk, liquidity cycle, default cycle, credit cycle, NBER economic cycle

JEL Classification: C32, C52, C61, G12, G13 


\section{Introduction}

This paper focuses on the identification of liquidity and default regimes in the bond market during the 2002-2012 period, which covers the recent financial crisis and the 2009 NBER economic recession. The recent literature has assumed a strong link between the business cycle and the credit cycle (e.g. Hackbarth, Miao, and Morellec, 2006; Chen, 2010; Bhamra, Kuehn, and Strebulaev, 2010; Giesecke, Longstaff, Schaefer, and Strebulaev, 2011; Bhamra, Fisher, and Kuehn 2011; Dionne et al., 2011). Yet empirical evidence supports only the presence of an imperfect overlap between the credit cycle and the economic cycle. The credit cycle encompasses the entire recessionary period but often extends beyond the end of the recession. Nonetheless, the observed patterns of the credit cycle have to be explained using its main two drivers: the default cycle and the liquidity cycle. It would be interesting to know how these cycles behave during periods of financial distress and recession. Specifically, our main objective is to explain regime shifts in the credit risk factor of bond spreads by thoroughly analyzing these shifts in the default factor and in the liquidity factor. ${ }^{1}$

Maalaoui Chun, Dionne and François (2013) show that corporate bond spreads describe a long-lasting level regime that contains but outlasts NBER recessions. They also argue that regime shifts (especially for high-yield bonds with short maturities) are often detected before the effective starting date of the NBER economic recession. An important component in the credit regime stems from high default premiums observed during recessions. The empirical evidence also suggests that credit regimes contain a factor that qualifies as a forward-looking measure of financial and economic downturns.

In addition, the authors link their credit regimes to two economic indicators: the Senior Loan Officer Opinion (SLO) Survey, which captures capital market liquidity, and the Fed fund rate, which captures the state of monetary policy. The detected credit regime is almost always affected by credit supply effects but has feedback effects with monetary policy actions. Thus, the dynamics of the credit regime may result from changing liquidity conditions in the bond market.

Longstaff, Schaefer, and Strebulaev (2011) find that, since the railroad crisis in 18731875, historical patterns of default have constituted important economic phenomena that often repeat themselves. Longstaff, Mithal, and Neis (2005, LMN) support the idea that the default risk is the most important part of the corporate credit spread, using data before the financial crisis (2000-2001). However, Dick-Nielsen, Feldhutter, and Lando (2012, DFL) reach a different conclusion for the recent subprime crisis. They argue that since the onset of the subprime crisis, most of the credit spread has been due to the illiquidity of the bond market. This confirms the need to re-examine the relationship between default and liquidity risk in the bond market by modeling these risks distinctly and linking them to the credit risk premium (Han and Zhou, 2008).

\footnotetext{
${ }^{1}$ Saunders and Allen (2010), and Bernanke (2013) address this question without a formal analysis.
} 
We estimate the default risk of corporate bonds using information from credit default swap (CDS) contracts. The CDS contracts have the advantage of being more liquid than corporate bonds and thus embed new information concerning changes in the creditworthiness of the issuer more efficiently. ${ }^{2}$

Thus, a CDS premium is a timely reflector of the credit worthiness of the firm that issued the bond. Further, given that CDS are contracts rather than securities, the premium of a CDS contract is much less sensitive to effects of liquidity and market risks and effects of convenience yield than are corporate bond prices. Thus, CDS contracts are attractive from the point of view of estimating default risk. We closely follow LMN in constructing the individual default risk measure for each firm in our sample. Our study covers the period from 2002 to 2012, a much larger window than the 2000-2001 period in LMN (2005) or the 2005-2009 period in DFL (2012). As opposed to only considering the single 5-year CDS contract, following Chun and $\mathrm{Yu}$ (2013) we also analyze the whole term structure of CDS contracts for each firm when filtering out the firm-specific default risk measure.

To measure the liquidity premium we use the most comprehensive source of high frequency bond transactions provided by TRACE. We follow Han and Zhou (2008) and DickNielsen, Feldhutter, and Lando (2012) in measuring the liquidity component for each firm in our sample using several measures of liquidity. Relative to these contributions, our study covers the entire 2007-2009 financial crisis, the recent 2007-2009 NBER recession, as well as the aftermath period of the crisis (2009-2012), This allows us to study the characteristics of corporate bonds during an important period of recovery and debt restructuring. Finally, using the real-time regime detection technique of Maalaoui Chun, et al (2013), we extract distinct regimes of default and liquidity risk for the sample of firms in our study and contrast them with the credit risk regimes.

Our results show that, for corporate bonds, a first liquidity risk shift occurred at the beginning of the financial crisis period (07-2007) and a second more important shift occurred near the middle of the crisis period (06-2008). This second high-liquidity regime persists until the end of the financial crisis in 03-2009. This means that the first liquidity regime shift predates the NBER recession (12-2007 to 06-2009), as is the case with the date of the first corporate credit risk shift (09-2007). In fact, it is this first liquidity risk shift that seems to drive the predictive power of the credit risk shift on the 2007-2009 NBER recession.

Regarding the default risk regimes, an important regime shift occurred in June 2008, well after the beginning of both the financial crisis and the NBER recession starting date. The persistence of the default risk factor following both periods is much stronger than the persistence of the liquidity risk factor, which is in line with results found in the recent theoretical literature on dynamic structural default risk models (Hackbarth, Miao, and Morellec, 2006; Chen, 2010; and Bhamra, Kuehn, and Strebulaev, 2010). Our results also support monetary

\footnotetext{
${ }^{2}$ Detailed discussions on the differences between CDS premiums and corporate bond spreads can be found in Longstaff, Mithal, and Neis (2005) and Lando (2004).
} 
and credit supply effects models of Bhamra, Fisher and Kuehn (2011), Bernanke and Gertler (1989), King(1994), and Kiyotaki and Moore (1997).

The remainder of this paper is organized as follows. The next section reviews the credit risk literature by emphasizing two major components of credit risk - default risk and liquidity risk. Section III briefly outlines the model used to extract default risk from the information in CDS contracts. It also outlines the model used to measure liquidity risk and the regime shift detection technique. Section IV describes the TRACE data for bond transactions as well as the Markit data that includes all North American Financial CDS data for CDS contracts. Section V presents the results. Section VI concludes the paper. Technical details are reported in the Appendix.

\section{Literature review}

\section{II.1 Credit risk models}

Credit risk in this paper is referred to as the yield spread, i.e. the difference between the yield of a defaultable bond and the yield of the government bond with the same maturitiy (Duffee, 1998). This difference, also called a credit spread in the literature, measures the risk premium associated with the credit risk. This means that corporate bond investors ask for a higher yield on a corporate bond because they are exposed to additional risks and costs that do not affect a government bond (or any other equivalent benchmark; see for instance Hull et al., 2004). We assume that the government bond yield does not contain any premium related to currency devaluation, public debt or public deficit and liquidity (Ejsing, Grothe and Grothe, 2012). In other words, we do not cover the risk of sovereign debt. However, bonds issued by

firms, financial institutions and the government can all be affected by market risk (Fama and French, 1993).

Two important research questions in the recent financial literature are : 1) What portion of corporate yield spreads is directly attributable to default risk? and 2) How much of the corporate yield spread stems from other factors such as liquidity risk, tax, risk aversion, market risk, and macroeconomic risk? (Elton et al., 2001; Colin-Dufresne et al., 2001; Lando and Skodeberg, 2002; Huang and Huang, 2003; Driessen, 2005; Chen, Collin-Dufresne and Golstein, 2009; Dionne et al., 2010; among others). These issues are of fundamental importance from an investment perspective because corporate debt is one of the largest asset classes in financial markets (Longstaff et al., 2005). They are also important from a macroeconomic point of view because yield spreads are closely linked to business and monetary cycles. If credit spreads predict business cycles, it would be interesting to determine which its components is driving this predictive power. Finally, during the recent financial crisis, liquidity risk became important, especially in the banking industry. During that period, liquidity risk was significant for many financial assets (such as asset-backed commercial paper (ABCP) in Canada), and central banks had to use special policy measures to inject liquidity into the 
financial system. Finally, the new international regulatory framework for banks (Basel III, 2010) emphasizes the role of liquidity risk in computing regulatory capital.

Since the beginning of the 2000 s, the finance literature has distinguished between default risk and credit risk. Default risk is the risk that a bond issuer will not be able to pay the agreed coupons and principal during the life of the corporate bond. Default risk contains three main elements: 1) the probability of default (PD) and the related bond rating migration (BRM); 2) the expected value of the bond at default (EAD); and 3) the loss given default (LGD), which is the fraction of EAD that will not be recovered by the bondholder after default.

Before the 2000s, credit risk was considered as synonym to default risk. Yet, research has shown that credit risk cannot be explained only by historical default related variables. The default risk represents only a fraction of corporate credit spread which instantaneously represent the premium according to structural models. Even by adding additional candidates further suggested by more recent structural models, the literature has been able to explain around $25 \%$ to $85 \%$ of the yield spread, depending on the bond rating, the period considered, the nature of the data available, and the set of factors considered including the business cycle (Elton et al., 2001; Colin-Dufresne et al., 2001; Huang and Huang, 2003; Lando and Skodeberg, 2002; Dionne et al., 2010; Maalaoui-Chun, et al, 2010; Cenesizoglu and Essid, 2012). This phenomenon is now labeled as the Credit Risk Puzzle.

Liquidity risk has been documented as one of the important determinants of corporate bond credit spreads (e.g. Longstaff, Mithal, and Neis, 2005). Yet, the lack of transaction bond data necessary to measure this risk limited the empirical support of this hypothesis. During the recent financial crisis many structured financial products such as asset-backed commercial paper (ABCP) and collateralized debt obligations (CDO) became highly illiquid supporting the idea that liquidity risk is an important risk in the credit market.

The macroeconomic risk factor is also an important determinant of credit spread. A statistical link between business cycles and credit spread levels and volatility has been observed, however the causality between the business cycle and the credit cycle is not well established. For instance, as documented by Maalaoui-Chun, et al (2013), and Ng, (2013), there is no perfect concordance between business cycles and credit cycles. Credit cycles last often longer than business cycles. When recessions officially end, corporate yield spreads remain high for many months, meaning there is persistence in credit cycles. More importantly, because corporate bond spreads start to increase before economic recessions they can even be viewed as predictors of recessions.

Early contributions on decomposing credit spreads have been limited by the availability of bond data. Today, detailed data on bond transactions at high frequency become available. In addition, a larger set of credit derivatives is traded actively in financial markets providing researchers with alternative data sources to examine the dynamics of corporate yield spreads more closely.

LMN (2005) use information on credit default swaps (CDS) to separate the relative sizes 
of default and non-default components in corporate yield spreads. They assume that the CDS premium is an appropriate measure of default risk. A CDS is like an insurance contract that compensates the investor for losses arising from the default of a corporate bond. In such contracts, the owner of a corporate bond is the party buying protection by paying the seller of a CDS (usually an investment bank or an insurer) a fixed premium each period (usually a quarter) until either the bond defaults or the swap contract matures. In return, if the underlying firm defaults on its debt, the protection seller is obliged to buy the defaulted bond back from the CDS buyer at its par value. The protection seller usually loses a fraction (LGD) of the par value of the defaulting bond. ${ }^{3}$

LMN (2005) find that more than fifty percent of corporate yield spread is due to default risk. This result holds for all studied rating categories and is robust to the definition of the riskless curve. In particular, using credit spreads over Treasury yields, the default component represents $51 \%$ of the spread for AAA and AA rated bonds, 56\% for A-rated bonds, 71\% for BBB-rated bonds, and $83 \%$ for BB-rated bonds. These results contrast with those in Elton et al. (2001) and Huang and Huang (2003), who report that default risk accounts for only about $25 \%$ of the spread for investment-grade bonds, but they are similar to the findings of Dionne et al. (2010, 2011).

Using Treasury bond yields as a benchmark to compute credit spreads, LMN (2005) find evidence of a significant non-default component for every firm in the sample. This non-default component ranges from about 20 to 100 basis points. They argue that the non-default component of corporate bond spread is time varying and strongly related to measures of bondspecific illiquidity as well as to macroeconomic measures of bond market illiquidity, such as the size of the bid/ask spread and the principal amount outstanding of corporate bonds.

Dick-Nielsen, Feldhutter and Lando (DFL, 2012) show how the increase in corporate bond spreads during the subprime crisis can be attributed to escalating bond illiquidity. As a measure of illiquidity, they used an equally weighted sum of four liquidity variables normalized to a common scale and identified from principal component analysis. The four liquidity variables are measured quarterly and include the Amihud's measure of price impact, a measure of roundtrip cost of trading and the variability of the two measures. To analyze variations in credit spreads they considered different control variables such as default risk, taxes, and the general economic environment. Yet, they did not use CDSs sold on these bonds to measure default risk. The main conclusion in DFL work is that liquidity risk become very important after the subprime crisis especially for investment grade bonds. For speculative grade bonds, the total spread explained by liquidity risk was $24 \%$ during the pre-subprime period and $23 \%$ during the post-subprime crisis. However, for investment grade bonds, the ratio increased significantly between the two periods ranging from $3 \%$ to $8 \%$ during the pre-subprime period (according to the ratings) to $23 \%$ to $42 \%$ during the post-subprime crisis. The exception is AAA

\footnotetext{
${ }^{3}$ There are other equivalent settlement methods in the market that we do not discuss in our analysis (Lando, 2004).
} 
bonds, which varied from $3 \%$ to $7 \%$ between the two periods. They attribute this exception to a fly-to-quality phenomenon. They also obtained different results when considering bonds with different maturities with the largest variations between the pre and post subprime observed for bonds with 10 to 30 years of maturity.

DFL also looked at the effect of the nature of the bond underwriter and the industry origin on bond illiquidity. Specifically, they analyzed the illiquidity of bonds underwritten by Bear Stearns and Lehman Brothers and compared them with the illiquidity of bonds underwritten by other banks. They found a small effect for Bear Stearns, which was acquired by J.P. Morgan. However, they document a big jump in the illiquidity index of bonds underwritten by Lehman Brothers during the period around the default of the bank followed by some persistence after the bankruptcy date (September 15, 2008). By comparing the illiquidity index of bonds of industrial firms with the index of bonds of financial firms, they find that bonds of financial firms were more liquid before the onset of the financial crisis in July 2007 and became less liquid after that date. In conclusion, these authors observed that bond spreads increased considerably during the financial crisis and found that bond illiquidity contributed significantly to that widening.

Chiaramonte and Casu (2013) analyze the determinants of CDS spreads during the period 01-01-2005 to 30-06-2011, including the financial crisis of 01-07-2007 to 31-03-2009. The model is limited to bank-specific balance sheet ratios as possible determinants of the spreads. Their results indicate that Tier 1 capital and leverage are not significant over the period of analysis, while liquidity indicators are significant only during and after the financial crisis period. Liquidity is measured by two ratios: 1) Net loans/ deposits and short-term funding (\%), and 2) Liquid assets/deposits and short-term funding (\%). Interestingly, during the financial crisis only the first definition of liquidity is significant reflecting the high leverage in the credit market. However, in the post-crisis period both definitions of liquidity become significant. According to these results, the authors argue that liquidity risk become a major concern since Basel III.

Recent papers have analyzed the speed of convergence to stable liquidity conditions in the stock market. For instance, following a liquidity shock, how many quote updates are necessary for transaction costs or market depth to return to their pre-shock levels? (Degryse et al. 2005; Wuyts, 2012; Foucault et al., 2005). In the same spirit, Beaupain and Durré (2013) analyze the resilience in the money market. ${ }^{4}$ They examine the determinants of the spread between the overnight interest rate and the European Central Bank (ECB) policy rate. By definition, this spread is affected only by market liquidity conditions. In resilient markets, liquidity shocks should be absorbed without affecting prices. Further, resilient markets attract market participants and favor trading thus speeding up convergence to stable liquidity conditions in periods of liquidity distress. Beaupain and Durré (2013) main results identify

\footnotetext{
${ }^{4}$ According to Kyle (1985) liquidity is related to 1) tightness (transaction costs), 2) depth and 3) resiliency of financial assets (see also Hasbrouck, 2009).
} 
liquidity, market activity and the institutional setting of the ECB's refinancing operations as significant determinants of the observed resiliency regimes. They also show how the speed of mean reversion of market liquidity affects the yield curve in the euro zone. Finally, these results highlight the interplay between the money market and the central banks and their role in efficiently providing banks with stable liquidity conditions in both normal and stress periods around the financial crisis. ${ }^{5}$

\section{II.2 Liquidity risk and default risk during the 2007-2009 financial crisis}

To interpret our statistical results we briefly chronicle the major events during the recent financial crisis. Difficulties started in the United States when housing prices began to decrease in 2006 following a rapid increase in interest rates intended to reduce inflation. Many home owners who contracted subprime loans went bankrupt. Because these loans were transferred to financial markets via securitization, banks did not screen and monitor these risks carefully. Loans were allowed without down payments and with little analysis of borrowers' credit capacity and income. Moreover, the excessive use of short-term funding and the increased use of CDSs concentrated risk within a few big financial institutions (Bernanke, 2013; Saunders and Allen, 2010).

The US government and the Federal Reserve did not control the financial system adequately during that mortgage crisis period. No concrete action was taken to reinforce banks' monitoring and managing of their different risks, and to compel them to hold adequate capital. The Federal Reserve also did not fully play its role in ensuring the stability of the financial system. The source of the problem was mainly related to the non-transparency of the structured financial markets and poor risk management of structured financial products (Dionne, 2013). Nobody knew where structured assets such as ABCP and CDOs were sold via OTC (Over-The-Counter Transactions); and who would incur the losses, thus creating great uncertainty in financial markets (Acharya et al 2013; Bernanke, 2013; Saunders and Allen, 2010).

Many regulatory failures accelerated the crisis. The rollover of ABCP, issued by Special Investment Vehicles, was supposed to be financed and guaranteed by commercial banks. However, such guaranties did not exist because they were not required by the regulation. In fact, many ABCP issues were not adequately documented (Chant, 2008, 2013). Moreover, during the crisis, banks sustained severe losses and the market value of their equity collapsed. These banks continued to pay dividends instead of keeping capital because, according to the regulatory standards, they were well capitalized (Acharya, 2013).

Banks were rapidly exposed to liquidity risks during the financial crisis (Acharya et al

\footnotetext{
${ }^{5}$ Stulz (2010) reviews the role of CDSs during the financial crisis. Allen et al, (2011) show that during the crisis, there was no variation in short-term spreads for Canadian financial institutions, although the 5-year CDS spreads varied substantially during the same period. They conclude that CDSs may not be appropriate instruments for providing information in very short periods of time. On the other hand, Chen et al, (2011) show there is strong interactions between interest rate risk and default risk measured by the term structure of CDSs with US data in a period preceding the financial crisis (2003-2007). See also Zorn et al. (2009) who document the interventions of the Canadian federal government in response to the financial crisis.
} 
2012). The liquidity crisis started during the summer of 2007. Banks were committed to credit lines that borrowers and structured product issuers could use at any time. Indeed, many firms and consumers used their credit line opportunity to reduce the effects of the crisis on their own portfolios. As a result, banks had less money for new lending. The repo market also failed during the financial crisis. Banks that used the repo market to finance purchases of structured products had two options: sell good quality securities in a down market or find expensive sources of credit to replace the repo market. These activities are the early indicators of a liquidity shortage in the financial market. Finally, the financial crisis accelerated when investors exercised the option not to roll over the short-term debt (Acharya, 2013).

The liquidity crisis turned into a default crisis in 2008. The nearly bankrupt bank Bear Stearns was sold to J.P. Morgan Chase with the help of the Federal Reserve. After failing to obtain a government bailout, the Lehman Brothers bank went bankrupt on September 15, 2008. That same day Merrill Lynch, another bank in financial difficulty, was acquired by Bank of America. The American Insurance Group (AIG), one of the biggest insurers in the world, was heavily involved in the CDS market and also had liquidity problems. It took several bailouts from the Federal Reserve to prevent its failure, yet this drove the economy into a deeper systemic downturn. A few days later, Washington Mutual was acquired by J.P. Morgan Chase bank, and Wachovia was taken over by Wells Fargo. During that period the Federal Reserve had to play its role of lender of last resort and provide liquidity to the financial market to stabilize the crisis (Bernanke, 2013).

Thus, in line with Saunders and Allen (2010), the period of the recent financial crisis can be decomposed into three major phases on which we base our empirical results. The first period characterizes the credit crisis in the mortgage market (06-2006 to 06-2007), the second period covers the period of the liquidity crisis (07-2007 to 08-2008), and the third period refers to the default crisis period (09-2008 to 03-2009). In this study we are mainly concerned with the second and third periods.

\section{Models}

In this section we present three models that will be used to decompose credit spread shifts into default shifts and liquidity shifts during the 2002-2012 period. We first present the default spread model where the spread is measured by the CDS premium of the corporate bonds, as in Longstaff et al (2005) and Chun and Yu (2013). Then we follow Dick-Nielsen et al's (2012) methodology to obtain an empirical measure of the bond illiquidity component of corporate bond spreads. Finally, we present the regime shift model of Maalaoui Chun et al (2013) that will be used to compare the regime shift periods of credit, default and liquidity risk in relation to the last financial crisis (07-2007 to 03-2009) and NBER recession (12-2007 to 07-2009). 


\section{III.1 The default premium of the debt issuer}

Default risk is the risk of reduction in bond market value caused by changes in the quality of bond issuers. This risk represents the fraction of the change in corporate bond yield spread associated with default risk. This fraction can be measured by the CDS premium on a corporate bond. ${ }^{6}$

A CDS is a financial instrument that provides insurance against the default of a reference security (the bond) or the reference credit (the issuer of the bond). A simple illustration of the CDS contract involves a protection buyer (the buyer of CDS protection) and a protection seller (the seller of CDS protection). The protection buyer buys protection against the default of the reference bond or of its issuer by taking a long position on the CDS contract. The protection buyer pays a periodic CDS premium to the protection seller until either the default of the reference entity occurs or the CDS contract reaches maturity. ${ }^{7}$

If default of the reference entity occurs before the maturity of the CDS contract, the protection seller buys the defaulted bond from the protection buyer at its face value. As noted by LMN in practice it is very common to assume that the CDS premium equals the default component of the bond issuer's credit spread. ${ }^{8}$ Using the reduced-form approach developed by Duffie and Singleton (1999, 2003), we represent the firm-specific intensity of default implied by the observed premium in a CDS contract.

The risk-neutral default intensity of the corporate bond follows a square-root diffusion (Cox-Ingersoll-Ross, 1985, CIR) process :

$$
d \lambda_{t}^{i}=\beta_{i}\left(\alpha_{i}-\lambda_{t}^{i}\right) d t+\sigma_{i} \sqrt{\lambda_{t}^{i}} d Z_{t}^{i} .
$$

where $\lambda^{i}$ is the intensity of the Poisson process governing the default of the reference issue $i$, $Z^{i}$ is a standard Brownian motion, and $\alpha_{i}, \beta_{i}, \sigma_{i}$ are CIR parameters capturing the dynamics of the default intensity of the reference issue $i$. We follow Chun and $\mathrm{Yu}$ (2013) and use the Kalman Filter approach to infer for each reference issue $i$ the CIR parameters corresponding to the whole observed term structure of CDS premia. ${ }^{9}$ We assume that the default-free interest rate that we denote $r_{t}$ is independent of $\lambda_{t}^{i}$. As documented in LMN, this assumption has little effect on the empirical results, and it greatly simplifies the model. Suppose firm $i$ may default at time $\tau_{i}$. Thus, at this time $\tau_{i}$, the bondholder recovers a fraction $\left(1-w_{i}\right)$ of the par

\footnotetext{
${ }^{6}$ Another method of measuring default risk is to compute its components (default probability (DP), exposure at default, (EAD) and loss given default (LGD)) directly by using bond data (Elton et al, 2001; Lando et al, 2002; Dionne et al, 2010).

${ }^{7}$ The International Swaps and Derivatives Association has defined six credit events that trigger settlement under the CDS contract. These events include bankruptcy of the reference entity, failure to pay interest or principal when due, debt restructuring unfavorably affecting the credit holder, obligation default, obligation acceleration, and repudiation/moratorium.

${ }^{8}$ We do not consider counterparty risk of CDS writers although some of them had solvency problems during the recent financial crisis. Since we are mainly interested in the study of regime shifts, this should not affect our results significantly.

${ }^{9}$ See Duan and Simonato (2004) for more details on the use of the Kalman Filter.
} 
value of the bond. Suppose the protection buyer makes quarterly payments of $s_{i} \equiv \frac{s_{i}^{*}}{4}$ on the CDS at times $0, t_{1}, \cdots, t_{n}$ until the maturity of the contract or the default event, whichever comes first. Thus, we can write the present value of the premium leg of the $\operatorname{CDS} P\left(s_{i}, T\right)$ as follows:

$$
P\left(s_{i}, T\right)=E\left(\sum_{t_{i}=1}^{t_{n}} e^{-\int_{0}^{t_{i}} r_{s} d s} 1_{\left\{\tau_{i}>t_{i}\right\}} s_{i}\right) .
$$

The independence assumption between $r_{t}$ and $\lambda_{t}^{i}$ allows us to rewrite Equation (2) as:

$$
\begin{aligned}
P\left(s_{i}, T\right) & =s_{i} \sum_{t_{i}=1}^{t_{n}} E\left(e^{-\int_{0}^{t_{i}} r_{s} d s}\right) E\left(e^{-\int_{0}^{t_{i}} \lambda_{t}^{i} d s}\right) \\
& =s_{i} \sum_{t_{i}=1}^{t_{n}} D\left(t_{i}\right) E\left(e^{-\int_{0}^{t_{i}} \lambda_{t}^{i} d s}\right)
\end{aligned}
$$

where $D\left(t_{i}\right)$ is the discount factor, i.e. the price of a nondefaultable zero-coupon bond with maturity $t_{i}$ and face value of $\$ 1$. In case of default at time $\tau_{i}$, the recovery on the reference entity per unit of par value is $\left(1-w_{i}\right)$ so that the protection seller pays $w_{i}$ in default. The value of the protection leg can then be expressed as follows:

$$
\begin{aligned}
P\left(w_{i}, T\right) & =E\left(e^{-\int_{0}^{\tau_{i}} r_{s} d s} 1_{\left\{\tau_{i} \leq t_{n}\right\}} w_{i}\right) \\
& =w_{i} \int_{0}^{t_{n}} E\left(e^{-\int_{0}^{\tau_{i}} r_{s} d s}\right) E\left(\lambda_{t} e^{-\int_{0}^{t} \lambda_{s} d s}\right) d t \\
& =w_{i} \int_{0}^{t_{n}} D\left(t_{i}\right) E\left(\lambda_{t} e^{-\int_{0}^{t} \lambda_{s} d s}\right) d t
\end{aligned}
$$

where 1 is the default indicator. Following LMN, we rewrite Equation (3) and Equation (4) in terms of the diffusion parameters in Equation (1). It follows that:

$$
\begin{gathered}
P\left(s_{i}, T\right)=s_{i} \sum_{t_{i}=1}^{t_{n}} D\left(t_{i}\right) A_{i}\left(t_{i}\right) e^{B_{i}\left(t_{i}\right) \lambda_{0}^{i}}, \\
P\left(w_{i}, T\right)=w_{i} \int_{0}^{t_{n}} D\left(t_{i}\right)\left(G_{i}\left(t_{i}\right)+H_{i}\left(t_{i}\right) \lambda_{0}^{i}\right) e^{B_{i}(t) \lambda_{0}^{i}} d t,
\end{gathered}
$$

where $A_{i}\left(t_{i}\right), B_{i}\left(t_{i}\right), G_{i}\left(t_{i}\right)$, and $H_{i}\left(t_{i}\right)$ are expressed in terms of the CIR parameters $\left(\alpha_{i}, \beta_{i}, \sigma_{i}\right)$ in Equation (1) and their functions $A, B, G, H$ are given in the Appendix.

Given that the CDS contract has zero net value at inception, we can express the CDS premium $s_{i}$ in terms of the default intensity $\lambda_{0}^{i}$ by equating the values of the two legs in the 
CDS contract

$$
s_{i}=\frac{w_{i} \sum_{t_{i}=1}^{n} D\left(t_{i}\right)\left(G_{i}\left(t_{i}\right)+H_{i}\left(t_{i}\right) \lambda_{0}^{i}\right) e^{B_{i}\left(t_{i}\right) \lambda_{0}^{i}}}{\sum_{t_{i}=1}^{n} D\left(t_{i}\right) A_{i}\left(t_{i}\right) e^{B_{i}\left(t_{i}\right) \lambda_{0}^{i}}} .
$$

where all parameters are as defined above. ${ }^{10}$ If $\lambda_{0}^{i}$ is not stochastic, $s_{i}=\lambda_{0}^{i} \times w_{i}$, the expected loss of the corporate bond. Otherwise, $s_{i}$ is the weighted present value of $\lambda_{0}^{i} \times w_{i}$ and is lower than $\lambda_{0}^{i} \times w_{i}$ because of the negative correlation between $\lambda_{0}^{i}$ and $e^{B_{i}\left(t_{i}\right) \lambda_{0}^{i}}$ The expression in (6) allows us to estimate the firm specific default intensity $\lambda_{0}^{i}$ using the whole term structure of observed CDS premia.

\section{III.2 The liquidity premium of the issuer}

The literature maintains that the concept of liquidity has several dimensions, which cannot be summarized using a single measure of illiquidity. We follow DFL and construct the eight illiquidity measures defined in their study and use principal component analysis to specify a common illiquidity factor that will be used to approximate the liquidity premium of corporate bonds. ${ }^{11}$

The Amihud illiquidity measure This measure is defined by Amihud (2002) as the average ratio of the daily absolute return to the dollar daily trading volume. It characterizes the daily price impact of the order flow, i.e., the price change per dollar of daily trading volume. For each individual bond $i$, we compute the daily Amihud measure as follows:

$$
\operatorname{Amihud}_{t}^{i}=\frac{1}{N_{t}} \sum_{j=1}^{N_{t}} \frac{1}{Q_{j, t}^{i}} \frac{\left|P_{j, t}^{i}-P_{j-1, t}^{i}\right|}{P_{j-1, t}^{i}},
$$

where $N_{t}$ is the number of returns in each day $t, P_{j, t}^{i}$ (in $\$$ of $\$ 100$ par) denotes the $j t h$ transaction price of bond $i$ in day $t$ and $Q_{j, t}^{i}$ (in $\$$ million) the $j t h$ trading volume of bond $i$ in day $t$. This measure reflects how much prices move due to a given value of a trade. Thus, a very illiquid bond would have a very high Amihud measure. To construct the Amihud daily measures, we first apply the Han and Zhou (2008) filters. Specifically, we exclude transaction prices less than $\$ 1$ and higher than $\$ 500$. We exclude prices that are $20 \%$ higher than the median price of the same day or the previous day. We also exclude prices that are $20 \%$ lower than the median price of the same day or the previous day. After applying this filter, we verify that we have at least three transactions for each bond to obtain the daily Amihud measure. To obtain the monthly measures we take the median of daily measures.

\footnotetext{
${ }^{10}$ When default occurs between two payment dates, the protection leg value should be adjusted to account for the accrued payment.

${ }^{11}$ These illiquidity measures are commonly used in the literature. See Chen, Lesmond, and Wei (2007), Amihud (2002), Han and Zhou (2008), Feldhüter (2008), among many others.
} 
The Imputed Roundtrip Cost This second measure of illiquidity, introduced by Feldhüter (2009), is constructed to capture transaction costs in imputed roundtrip trades (IRC). The imputed roundtrip cost (IRC) is defined as

$$
\mathrm{IRC}=\frac{P_{\max }-P_{\min }}{P_{\max }}
$$

where $P_{\max }$ and $P_{\min }$ denote the maximum and minimum trading prices during a unique roundtrip trade. The idea behind this measure is as follows. When during the same day a bond with the same volume trades two or three times but does not trade again at the same volume on that day, the trade is considered part of an imputed roundtrip trade. Thus, in the imputed roundtrip trade, the difference between the highest and lowest transaction prices reflects the transaction fees of the dealer or the bid-ask spread for that trade. For each day, we estimate the IRC as the average of daily estimates of IRC for different transaction volumes.

The Amihud liquidity risk and the IRC liquidity risk These two liquidity risks are measured through the standard deviation of the Amihud measure and the imputed roundtrip cost (IRC) respectively. The two measures capture the variability of bond illiquidity, yet provide a sense of possible future illiquidity levels. We construct the daily liquidity risk measures using a rolling window of 21 trading days. To obtain monthly measures, we take the average across the month.

The Roll measure of the bid-ask spread Before November 2008, there was no indicator for whether the observed transaction price was a bid or an ask price. As a substitute, we use the implicit bid-ask spread measure following Roll (1984) over the 2002-2012 period. Under certain assumptions, the Roll measure infers the effective bid-ask spread directly from transaction prices: ${ }^{12}$

$$
\operatorname{Roll}_{t}^{i}=2 \sqrt{-\operatorname{cov}\left(\Delta P_{t}^{i}, \Delta P_{t-1}^{i}\right)} .
$$

where $\Delta P$ denotes changes in transaction prices. The daily Roll measure is calculated using a rolling window of 21 trading days with at least four transactions in the window to be sure the measure is well-defined.

The average holding time of a bond We measure trading intensity using the daily turnover:

$$
\text { turnover }_{t}=\frac{\text { total trading volume }_{t}}{\text { amount outstanding }}
$$

The turnover captures the trading intensity, which specifies assets that trade more frequently and thus are more liquid. The inverse of turnover (turnover $)_{t}$ can be interpreted as

\footnotetext{
${ }^{12}$ The Roll measure is based on the assumption of market efficiency. It also assumes that the probability distribution of observed price changes within a very short period is stationary (i.e. two months).
} 
the average holding time of a bond, which is another measure of illiquidity.

Bond's zero trading days Another measure of non trading intensity is the ratio of the number of zero trading days over the total number of days during a period. Thus, a higher ratio indicates that the corporate bond is less liquid. We obtain the daily zero-trading days measure using a rolling window of 21 trading days.

$$
\text { bond } \text { zero }_{t}=\frac{\text { number of bond zero trades within the rolling window }}{\text { number of days in the rolling window }}
$$

Firm's zero trading days Another measure of non-trading intensity is the firm's zero trading days, which counts the days in which none of the firm bond issues is traded in that day. Similar to the bond zero trades measure, we obtain the daily firm zero trades measure using a rolling window of 21 trading days.

$$
\text { firm } \text { zero }_{t}=\frac{\text { number of firm bonds zero trades within the rolling window }}{\text { number of days in the rolling window }}
$$

The liquidity premium We construct a liquidity premium using the relevant loadings obtained from principal component analysis of the above illiquidity definitions. Specifically, the liquidity premium (or illiquidity factor) is a linear combination of illiquidity loads obtained from principal component analysis. We define each measure as $l_{i t}^{j}$, where $i$ defines the corporate bond, $t$ defines the day, and $j$ defines the liquidity definition. Each measure is then normalized and leads to $\bar{l}_{i t}^{j}=\frac{l_{i t}^{j}-\mu_{j}}{\sigma_{j}}$, with $\mu_{j}$ and $\sigma_{j}$ defining the mean and the volatility of the liquidity measure $j$ across the different bonds and days. Finally, we define the daily measure of the bond specific illiquidity factor as a linear combination of the normalized illiquidity measures.

$$
\varsigma_{i t}=\sum_{j=1}^{J} \bar{l}_{i t}^{j}
$$

where $J$ is the number of liquidity measures that will be retained from the principal component analysis.

\section{III.3 Default and liquidity regime detection}

The econometrics literature on structural changes provides a wide range of techniques for detecting break dates in time series. ${ }^{13}$ In this article we use the technique of Maalaoui Chun, et al (2013), which has the advantage of detecting possible break points in real time or when new data arrives. The non-parametric technique is a data-driven analysis in that it detects random regime shifts and can be classified among random regime models. It does not require

\footnotetext{
${ }^{13}$ See for instance Gordon and Pollak (1994), Bai and Perron (1998), (2003), Chib (1998), Chen, Choi, and Zhou (2005), Perron and Qu (2006), Pesaran, Pettenuzzo, and Timmermann (2006), Davis, Lee, and Rodriguez-Yam (2008), Giordani and Kohn (2008), Maheu and McCurdy (2009), and Bai (2010).
} 
any a priori assumptions about the timing or the number of detected regimes, and it does not require the regime to switch back to its previous level. Another feature of this technique is its ability to detect economic shocks affecting the level and the volatility of time series distinctly from one another. We can thus detect new regimes in the data and attempt to link these regimes to economic phenomena that remain unexplained.

Consider that data on a risk premium is represented by the following time series $\left\{Y_{t}, t=\right.$ $1, \ldots, n\}$. Suppose $Y_{t}$ is described by an autoregressive model:

$$
Y_{t}-f_{t}=\rho\left(Y_{t-1}-f_{t-1}\right)+\varepsilon_{t},
$$

where $f_{t}$ captures a potentially time-varying mean, $\rho$ is the autocorrelation coefficient, and $\varepsilon_{t} \sim N\left(0, \sigma^{2}\right)$. If time $t=c$ is a breakpoint where the distribution of the data changes, then the mean level $f_{t}$ can be expressed as:

$$
f_{t}=\left\{\begin{array}{l}
\mu_{1}, t=1,2, \ldots, c-1, \\
\mu_{2}, t=c, c+1, \ldots, n .
\end{array}\right.
$$

where the null hypothesis for a shift at time $c$ is performed using a two-sample $t$-test. The presence of a positive autocorrelation coefficient in equation (14), can generate false regime detections in the data. When the underlying data contain a stationary first-order autoregressive process with a positive autocorrelation coefficient, such a process is known as a red noise process. Thus, the removal of red noise, which involves estimating the AR(1) coefficient, is an important preliminary step that facilitates the accurate detection of regime shifts in the data. After the AR(1) coefficient is accurately estimated and the red noise is removed, the filtered time series is then processed with the regime shift detection method. (See Maalaoui Chun et al., 2013, for more details).

To detect a level regime, we start by defining the sample mean $\bar{Z}_{\text {cur }}$ of the first sequence of the data of length $m .{ }^{14}$ Let $\Delta$ be the difference between the mean values of two subsequent sequences that would be statistically significant at the level $\alpha_{\text {mean }}$ according to the Student $t$-test:

$$
\Delta=t_{\alpha_{\text {mean }}}^{2 m-2} \sqrt{2 \bar{s}_{m}^{2} / m}
$$

where $m$ is the initial cut-off length of regimes similar to the cut-off point in low-pass filtering, $\bar{s}_{m}^{2}$ is the sample variance, and $t_{\alpha_{\text {mean }}}^{2 m-2}$ is the value of the two-tailed $t$-distribution with $(2 m-2)$ degrees of freedom at the given probability level $\alpha_{\text {mean }}$. During the test, the sample mean of the current regime $\bar{Z}_{\text {cur }}$ is known but the mean value of the new regime $\bar{Z}_{\text {new }}$ is unknown. The shift in the level occurs if the current value tested $Z_{c u r}$ is outside the critical threshold

\footnotetext{
${ }^{14}$ We previously check that the filtered data do not suffer from statistical issues related to the distribution of the data in each regime, heteroskedasticity of the residuals and square residuals. These issues are further discussed in Maalaoui Chun et al (2013).
} 
] $\bar{Z}_{\text {crit }}^{\downarrow}, \bar{Z}_{\text {crit }}^{\uparrow}[$

$$
\begin{aligned}
& \bar{Z}_{\text {crit }}^{\uparrow}=\bar{Z}_{c u r}+\Delta, \\
& \bar{Z}_{\text {crit }}^{\downarrow}=\bar{Z}_{c u r}-\Delta,
\end{aligned}
$$

where $\bar{Z}_{\text {crit }}^{\uparrow}$ is the critical mean if the shift is upward and $\bar{Z}_{\text {crit }}^{\downarrow}$ is the critical mean if the shift is downward. However, if the current value $Z_{\text {cur }}$ is inside the range $] \bar{Z}_{\text {crit }}^{\downarrow}, \bar{Z}_{\text {crit }}^{\uparrow}$, then we reject the null for a shift at $t_{c u r}$ and we conclude that the current regime has not changed. In this case, the value $Z_{\text {cur }}$ is included in the current regime and the test continues with the next value. However, if the current value $Z_{c u r}$ is greater than $\bar{Z}_{\text {crit }}^{\uparrow}$ or less than $\bar{Z}_{\text {crit }}^{\downarrow}$, the time $t_{c u r}$ is marked as a potential change point and the subsequent data are used to confirm or reject this hypothesis using the Regime Shift Index $(R S I)$ that represents a cumulative sum of normalized anomalies relative to the critical mean $\bar{Z}_{\text {crit }}$ :

$$
R S I=\frac{1}{m \bar{s}_{m}} \sum_{i=t_{c u r}}^{j}\left(Z_{i}-\bar{Z}_{\text {crit }}\right), j=t_{c u r}, t_{c u r}+1, \ldots, t_{c u r}+m-1 .
$$

If at any time during the testing period from $t_{c u r}$ to $t_{c u r}+m-1$ the $R S I$ turns negative when $\bar{Z}_{\text {crit }}=\bar{Z}_{\text {crit }}^{\uparrow}$ or positive when $\bar{Z}_{\text {crit }}=\bar{Z}_{\text {crit }}^{\downarrow}$, the null hypothesis for a shift at $t_{c u r}$ is rejected. We include the value $Z_{\text {cur }}$ in the current regime and continue the test with the next value at $t_{c u r}=t_{m}+2$. Otherwise, time $t_{c u r}$ is declared a change point and is significant at least at the confidence level $\alpha_{\text {mean }}$. The subsequent regime then becomes the current regime and the test continues with the new data point.

\section{Data}

In this research we use two main data sets.

The TRACE database: This database became available only in July 2002. The TRACE database reports high frequency data and contains information about almost all trades in the secondary over-the-counter market for corporate bonds, accounting for $99 \%$ of the total trading volume. Our data from TRACE cover the period from July 2002 to December 2012. ${ }^{15}$ We employ the filter proposed by Dick-Nielsen (2009) to correct for reporting errors, which are shown to include a substantial bias in liquidity measures to reflect a more liquid bond market. ${ }^{16}$ In addition, as Dick-Nielsen (2009) noted, duplicates of the so-called agency transactions may introduce a downward bias in the Turnover measure when compared with the values reported in the FINRA TRACE fact book. Given that we use Turnover in our liquidity

\footnotetext{
${ }^{15}$ Although the full dissemination of bond transaction prices is completed in October 2004, we include transaction prices before that date if we can match the bond with a CDS contract.

${ }^{16}$ For instance, Dick-Nielsen (2009) shows that the magnitude of the median error ranges between $7.4 \%$ and $14.6 \%$ respectively for the average daily turnover and the quarterly Amihud measure.
} 
measures, we also filter out agency transaction duplicates.

The CDS database: Data for CDS contracts are obtained from Markit. We thus have a rich dataset on CDS spreads for a wide range of firms and banks and over the entire term structure. Maturities are from 6 months to 10 years. The data have a daily frequency and cover the period from 2002 to 2012 . We use the whole term structure to extract the $\lambda$-intensity of each issuer. Trading days are defined by the time schedule of the NYSE.

\section{Estimation results and discussion}

\section{V.1 Statistics for credit risk}

Figure 1 reports the evolution of credit spreads from January 2007 to April 2009. It also indicates the main developments associated with the financial crisis during that period. ${ }^{17}$ We note the three periods of the financial crisis identified by Saunders and Allen (2010): 1) Mortgage market crises before 07-2007; 2) Liquidity crisis (07-2007 to 08 2008); and 3) Default crisis (09-2008 to 03-2009).

We observe two important jumps in credit spreads dynamics during the financial crisis period that are associated with the periods of liquidity and default crises (07-2007 to 03-2009). The first jump starts during the Fall of 2007 and is associated with the freeze of ABCPs and the CDO downgrades. In March 2008, the bank Bear Stearns experienced difficulties and Lehman Brothers failed in September 2008, which corresponds to the starting date of the second jump. AIG was rescued in the same period, as were other banks. The corporate bond spreads continued to increase until the end of 2008, when the Federal Reserve started to inject liquidity in the market. In the reminder of the paper we will identify the financial crisis as the sub-period from 07-2007 to 03-2009 to concentrate on liquidity and default crises.

\section{[Insert Figure 1 about here]}

The recession during 2001 (03-2001 to 11-2001) generated a long recovery period in the industrial market after the end of that recession. Many high technological firms had great difficulties recovering their previous growth. This is why corporate credit spreads were still high during 2002 and 2003, representing a strong persistence period in credit risk (see Figure 2). In fact, corporate credit spreads were higher during the period following the 2001 recession than during the recession itself (see Maalaoui Chun et al, (2013) for more details). Then, credit spreads were low until the middle of 2007, and began to increase sharply in the second period of the financial crisis identified as the liquidity crisis (07-2007 to 08-2008) by Saunders and Allen (2010). It seems that the 2006-2007 credit crisis in the mortgage market before the liquidity crisis of 2007-2008 had little impact on the corporate bond market and that the 2005 increase in interest rates had not effect on corporate bond spreads.

\footnotetext{
${ }^{17}$ A similar figure is illustrated in Saunders and Allen (2010), yet they use the Kansas City of Financial Distress Index which looks very similar to our bond spread measure.
} 
Panel B of Figure 2 presents the evolution in the time series of credit spreads around the 2007-2009 financial crisis period while Panel A presents the same time series around the NBER recession. Again, we observe two important jumps in credit spreads during the liquidity and default crisis periods. The first one precedes the start of the NBER recession from 12-2007 to 06-2009 and the second one is during the recession. It seems that that credit risk had predictive power on the recession. Is this due to default risk or liquidity risk in the banking system? We shall answer this question later. Finally, there is another important persistence effect after the 2009 economic recession, and our regime shift detection model should be able to separate the default risk effect from the liquidity risk effect in this persistence.

\section{[Insert Figure 2 about here]}

\section{V.2 Credit risk regimes}

For our regime detection, we use an initial cut-off length of six data points $(m=6)$, and a Huber parameter of two $(h=2)$ which controls for outliers in credit spreads series. We also prewhitened the data before applying the regime detection technique to reduce the possibility of detecting false regimes. All the detected regimes are significant at least at the $95 \%$ confidence level $(\alpha=0.05)$. Shift points for credit spreads are reported in Table 1, Panel A and can be summarized as follows.

\section{[Insert Table 1 about here]}

A first positive shift is detected in Septemebr 2007, three months before the official start of the NBER recession and two months following the official starting date of the financial crisis. The level of credit spreads increased from $1.60 \%$ to $3.66 \%$. A second shift occured in October 2008 increasing the level to $7.95 \%$. This second shift seems to reflect the starting official date of the default crisis in September 2008. The two positive credit spread regimes last for 13 months (first regime) and seven months (second regime). In May 2009, we detect a first negative regime. The level of credit spreads decreased from $7.95 \%$ to $4.40 \%$ but considered still high relative to its level before the crisis period (1.60\%). This first negative shift came two months after the official end of the default crisis in March 2009. A second negative shift occured in January 2010 and the level of credit spreads is reduced to $2.48 \%$, again still higher than the initial level of $1.60 \%$.

Our results are consistent with two important aspects of the credit spreads documented in the literature: the predictive aspect and the persistence aspect of credit spreads toward recessions. As noted earlier, the increase in the level of credit spreads preceeded the recession, and the high level regime persisted long time after the recession (Figure 3, Panel A) and the financial crisis period (Figure 3, Panel B). To understand the origins of these two aspects in the data, we break down these credit risk shifts into default and liquidity regime shifts. This allows us to obtain a more detailed interpretation of the driving forces of both crises. 
[Insert Figure 3 about here]

\section{V.3 Statistics and detection of default risk regimes}

Table 2 reports summary statistics for the daily CDS premiums of different maturities (6 months to 10 years), the recovery rates $\left(1-w_{i}\right)$, and the corresponding credit spreads $(C S)$.

[Insert Table 2 about here]

Figure 4 presents the CDS premiums of bonds issued by different investment banks and AIG around the NBER recession. The series of Lehman Brothers ends with its bankruptcy date, and those of Bear Stearns and Wachovia end with their acquisition dates by J.P. Morgan and Wells Fargo respectively. Merrill Lynch continues to operate under its original name even if it merged with Bank of America, and AIG still operates under its original name after being bailed out by the US government in September 2008. It is interesting to observe that even if all spreads increased significantly during the recession, none moved significantly before the recession. The liquidity risk crisis period identified by Saunders and Allen (2010) therefore does not seem to have affected these default premiums significantly. The variation in premiums may be related to the default risk of these institutions, and their relative value seems to support that observation. It is interesting to observe that the premiums of JP Morgan are much lower than those of the other institutions, and those of AIG were particularly high at the end of the recession period even after it was rescued by the US Government.

\section{[Insert Figure 4 about here]}

We illustrate the dynamics of the default risk factor from January 2001 to December 2012 in Figure 5. We plot the default factor obtained as an average of the $Q$-intensity of default obtained from our CDS data of all the firms in our sample for which CDS products were sold (129 firms including the six institutions in Figure 4). The shaded regions represent the NBER recession period (12-2007 to 06-2009) in Panel A and the financial crisis period (07-2007 to 03-2009) in Panel B. We obtained the $Q$-intensity for each firm by fitting the CDS data for different maturities (six months to ten years for each issuer in the dataset) into the LMN setting. For our regime detection, we use an initial cut-off length of six data points $(m=6)$ and a Huber parameter of two $(h=2)$ after prewhitening the data on the default factor. All the detected regimes are significant at least at the 95\% confidence level ( $\alpha=0.05)$.

Both the statistics of the $Q$-intensity factor and the level default regime clearly indicate that default risk was not important before June 2008. Interestingly, the first positive shift we detect is in June 2008 as shown in Table 1, Panel B. The default risk increased from $0.01 \%$ to $0.09 \%$. This high default risk regime lasts for seven months. A second shift is detected thereafter in January 2009. Although the shift is negative lowering the default risk from $0.09 \%$ to $0.06 \%$, it is still considered very high relative to the initial level of $0.01 \%$ before 
the crisis. The second high level regime lasts for 48 months. Therefore, the default risk exhibits a persistent pattern towards the NBER recession. This persistence in the default risk is consistent with the theoretical results of recent literature on dynamic structural models (Hackbarth, Miao, and Morellec, 2006; Chen, 2010; and Bhamra, Kuehn, and Strebulaev, 2010). The same persistence is also documented in monetary and credit supply effects models of Bhamra, Fisher and Kuehn (2011), Bernanke and Gertler (1989), King(1994), and Kiyotaki and Moore (1997).

[Insert Figure 5 about here]

\section{V.4 Statistics and detection of liquidity risk regimes}

Table 3 reports the summary statistics of the eight liquidity measures considered in this study: Amihud, IRC, Amihud Risk, IRC Risk, Roll, Turnover, Bond Zero trade, and Firm Zero trade. Table 4 reports the correlation coefficients between these measures. Noticebly, the higher correlations are between the Roll measure and the IRC (0.77) and IRC risk (0.73) measures. The correlations between the Amihud and Amihud Risk measures with the Roll measure and with IRC and IRC Risk measures are low.

\section{[Insert Table 3 and 4 about here]}

Figure 6 presents the evolution of our eight illiquidity measures during the 2002-2012 period along with the NBER recession (Panel A) and the financial crisis (Panel B) periods. The most important observed jumps are for Amihud, IRC and Roll measures of illiquidity. These measures combine information on transaction volumes and bid-ask spreads in the bond market during these periods. The volatility measures of IRC and Amihud risk are also sensitive to the financial crisis and recession periods. It is interesting to observe a disctinct pattern in the different liquidity measures. The IRC and IRC volatility exhibit two important jumps around the crisis periods -one before the NBER recession and one in the middle of the recession. These jumps capture the increase in bond transaction costs and the start of the liquidity shortage episode. Interestingly, the Amihud and Amihud Risk jumps are observed outside of both the NBER recessionary period and the financial crisis period. These Amihud jumps are likely to reflect a different episode of high liquidity distress after the official crisis periods.

\section{[Insert Figure 6 about here]}

Results of the principal component analysis of the illiquidity variables are shown in Table 5. Panel A presents the eigenvalues of the eight principal components corresponding to the eight illiquidity indicators presented in Section III.2. Panel B shows their corresponding eigenvectors. Results indicate that the first principal component explains $42 \%$ of total dependence. This first component includes the IRC measure, the IRC Risk measure, and the Roll measure, consistent with the correlation matrix in Table 4. We use the results of this 
first principal component to construct our measure for the liquidity factor. Specifically, the liquidity factor is obtained as the average of the IRC, the IRC risk, and the Roll measures.

\section{[Insert Table 5 about here]}

As for the default factor, we apply the regime detection technique to the liquidity factor. We also use an initial cut-off length of six data points $(m=6)$ and a Huber parameter of two $(h=2)$ after prewhitening the data on the liquidity factor. Results of the liquidity regime are illustrated in Figure 7. The plot spans from July 2002 to December 2012. The shaded region represents the NBER recession period in Panel A and the financial crisis period in Panel B. All the detected regimes are significant at least at the 95\% confidence level $(\alpha=0.05)$. We report the detected shift points in Table 1, Panel C.

\section{[Insert Figure 7 about here]}

The first positive shift in the liquidity factor is detected in July 2007 at the beginning of the financial crisis (July 2007) and few months before the beginning of the NBER recession (December 2007). This first positive shift reflects the beginning of a regime of high level of liquidity risk. A second positive shift is detected in June 2008 and the liquidity risk increased from $0.61 \%$ to $0.73 \%$ as measured by our liquidity factor. These two high regimes of liquidity distress last for 61 months (first regime) and 11 months (second regime). Interestingly, we also detect a first negative regime in Mars 2009, the official end date of the financial crisis (Saunders and Allen, 2010), yet few months before the NBER official end date (June 2009). The first negative shift reduced the level of liquidity risk from a high level of $0.73 \%$ to another high level of $0.52 \%$. Thus the bond market was in a high liquidity distress regime both during the entire periods of NBER recession and financial crisis and also about two more years (19 months) after these periods. The high liquidity risk regime ended with the shift detected in February 2012, more than two years after the Federal Reserve intervention. After this second negative shift the liquidity risk factor returned to its level before the crisis $(0.42 \%$ in 2012 compared to $0.47 \%$ in 2002).

To sum up, our results confirm that the financial crisis started with a liquidity shortage but this shortage was amplified in the middle of the financial crisis. Our results partially support the decomposition of the financial crisis between a liquidity risk period from July 2007 to August 2008 and a default risk period from September 2008 to March 2009. Specifically, our results suggest that the liquidity period starts from July 2007 but ends in February 2012 following the second negative shift in the level of the liquidity risk factor. The default risk period detected by the regime shift model lasts from June 2008 to January 2009, a period that is very close to Saunders and Allen's (2010) default period. Finally, we notice that the liquidity risk crisis preceded the NBER recession period while the default crisis period started after the beginning of the NBER recession period. Therefore, we conclude that the predictive aspect of credit spreads on the 2009 NBER recession stems from the liquidity risk instead of default risk. 


\section{VI. Conclusion}

This paper analyzes credit risk regimes in the corporate bond market during the period 20022012 that includes the last financial crisis and the last NBER recession. Our goal is to explain the sources of corporate bond regime shifts by analyzing two of their components in detail: default and liquidity regime shifts.

By superimposing credit regimes on liquidity regimes and default regimes, we link, contrast and discuss the most important credit-related cycles in the bond market and study their behavior at the onset of economic recessions. Our analysis highlights the nature of the credit regime component, which serves as a forward-looking measure of financial and economic downturns. Specifically, we document the question of whether it is possible to attribute this characteristic of credit spreads to predict economic recessions to a shift in the liquidity risk or a shift in the default risk of the bond market. Our results offer new insights into developing dynamic structural equilibrium models for credit risk as well as for modeling the empirical dynamics of the credit risk premium. To our knowledge, no previous work has directly linked the credit regime to both default and liquidity regimes.

Our results show that two liquidity risk shifts occurred during the financial crisis period of 07-2007 to 03-2009: one at the beginning of the financial crisis period (07-2007) and a second more important one occurred in the middle of the crisis period (06-2008). This means that the first liquidity regime shift occurred before the NBER recession (12-2007 to 06-2009). This first liquidity regime shift seems to explain the predictive power of credit risk on the 2007-2009 NBER recession.

Regarding the default risk regimes, an important regime shift occurred in June 2008, well after the beginning of both the financial crisis and NBER recession starting dates. Yet the persistence effect of the default risk factor after both periods seems much stronger than the persistence effect of the liquidity risk factor, which is consistent with the recent theoretical literature on dynamics structural default risk models.

These preliminary results are very encouraging. They indicate that our new regime shift detection methodology adequately captures the shifts in credit, default and liquidity risks. They also show that rating and pricing models of corporate bonds must integrate a liquidity factor in their analysis, and not only a default factor. Finally they confirm the objective of Basel III to include liquidity risk in the computation of regulatory capital

Many extensions of our analysis are worth doing. We consider four of them here. First, it would be interesting to know the proportions of default risk and liquidity risks in the total yield spread. The recent paper by Dick-Nielse, Feldhütter and Lando (2012) shows that liquidity risk may have represented up to $40 \%$ of the credit spread before and after the subprime crisis (2005-2009). Although they controlled for default risk in their analysis, they did not explicitly analyze the proportion of default risk in the total credit spread.

Second, it would be interesting to separate the CDSs sold by the institutions in financial difficulty from other sellers to see how the CDS premium is explained not only by the default 
risk of the bond issuer but also by the default risk of the protection seller. It would also be important to verify if the CDS premiums contain liquidity risk. Finally, our model does not consider systemic risk. Recently, Allen et al (2012) showed that aggregate systemic risk exposure of the banking sector can predict microeconomic downturns. Extending our regime shift detection model to dependent risks would represent a major extension of our approach.

\section{Appendix: Estimation details of the default model}

Following Longstaff, Mithal, and Neis (2005), the default time $\tau_{i}$ follows a CIR process with intensity $\lambda_{t}^{i}$ :

$$
d \lambda_{t}^{i}=\beta_{i}\left(\alpha_{i}-\lambda_{t}^{i}\right) d t+\sigma_{i} \sqrt{\lambda_{t}^{i}} d Z_{t}^{i} .
$$

Then, the value of the premium leg can be expressed as follows:

$$
\begin{aligned}
P\left(s_{i}, T\right) & =s_{i} \sum_{t_{i}=1}^{t_{n}} E\left(e^{-\int_{0}^{t_{i}} r_{s} d s}\right) E\left(e^{-\int_{0}^{t_{i}} \lambda_{t}^{i} d s}\right) \\
& =s_{i} \sum_{t_{i}=1}^{t_{n}} D\left(t_{i}\right) E\left(e^{-\int_{0}^{t_{i}} \lambda_{t}^{i} d s}\right) \\
& =s_{i} \sum_{t_{i}=1}^{t_{n}} D\left(t_{i}\right) A_{i}\left(t_{i}\right) e^{B_{i}\left(t_{i}\right) \lambda_{0}^{i}}
\end{aligned}
$$

and, the value of the protection leg can be expressed as follows:

$$
\begin{aligned}
P\left(w_{i}, T\right) & =E\left(e^{-\int_{0}^{\tau_{i}} r_{s} d s} 1_{\left\{\tau_{i} \leq t_{n}\right\}} w_{i}\right) \\
& =w_{i} \int_{0}^{t_{n}} E\left(e^{-\int_{0}^{\tau_{i}} r_{s} d s}\right) E\left(\lambda_{t} e^{-\int_{0}^{t} \lambda_{s} d s}\right) d t \\
& =w_{i} \int_{0}^{t_{n}} D\left(t_{i}\right) E\left(\lambda_{t} e^{-\int_{0}^{t} \lambda_{s} d s}\right) d t \\
& =w_{i} \int_{0}^{t_{n}} D\left(t_{i}\right)\left(G_{i}\left(t_{i}\right)+H_{i}\left(t_{i}\right) \lambda_{0}^{i}\right) e^{B_{i}(t) \lambda_{0}^{i}} d t,
\end{aligned}
$$

where $D\left(t_{i}\right)$ is the discount factor, $\left(1-w_{i}\right)$ is the recovery on the reference entity per unit of par value, 1 is the default indicator, and $A(t), B(t), G(t), H(t)$, are funtions of the CIR 
parameters $(\alpha, \beta, \sigma)$ :

$$
\begin{aligned}
& A(t)=e^{\frac{\alpha(\beta+\phi)}{\sigma^{2}} t}\left(\frac{1-\kappa}{1-\kappa e^{\phi t}}\right)^{\frac{2 \alpha}{\sigma^{2}}} \\
& B(t)=\frac{\beta-\phi}{\sigma^{2}}+\frac{2 \phi}{\sigma^{2}\left(1-\kappa e^{\phi t}\right)}, \\
& G(t)=\frac{\alpha}{\phi}\left(e^{\phi t}-1\right) e^{\frac{\alpha(\beta+\phi)}{\sigma^{2}} t}\left(\frac{1-\kappa}{1-\kappa e^{\phi t}}\right)^{\frac{2 \alpha}{\sigma^{2}+1}}, \\
& H(t)=e^{\frac{\alpha(\beta+\phi)+\phi \sigma^{2}}{\sigma^{2}} t}\left(\frac{1-\kappa}{1-\kappa e^{\phi t}}\right)^{\frac{2 \alpha}{\sigma^{2}}+2},
\end{aligned}
$$

and

$$
\phi=\sqrt{2 \sigma^{2}+\beta^{2}}, \kappa=\frac{\beta+\phi}{\beta-\phi} .
$$

Note that $H(t)=-A(t) B^{\prime}(t)$ and $G(t)=-A^{\prime}(t)$.

\section{References}

[1] Acharya, Viral (2013) 'Understanding Financial Crises: Theory and Evidence from the Crisis of 2007-8.' NBER Reporter 1

[2] Acharya, Viral, Philipp Schnabl, and Gustavo Suarez (2013) 'Securitization without Risk Transfer,' Journal of Financial Economics 107, 515-536

[3] Acharya, Viral, Yakov Amihud, and Sreedhar T. Bharath (2012) 'Liquidity Risk of Corporate Bond Returns: A Conditional Approach.' Journal of Financial Economics, forthcoming. Available at SSRN: http://papers.ssrn.com/sol3/papers.cfm?abstract_id=1612287

[4] Allen, Jason, Ali Hortaçsu, and Jakub Kastl (2011) 'Analyzing Default Risk and Liquidity Demand during a Financial Crisis: The Case of Canada.' Working Paper 2011-17, Bank of Canada

[5] Allen, Linda, Turan G. Bali, and Yi Tang (2012) 'Does Systemic Risk in the Financial Sector Predict Future Economic Downturns?' Review of Financial Studies 25, 3000-3036

[6] Amihud, Yakov (2002) 'Illiquidity and Stock Returns: Cross-Section and Time-Series Effects.' Journal of Financial Markets 5 , 31-56

[7] Bai, Jushan (2010) 'Common Breaks in Means and Variances for Panel Data.' Journal of Econometrics 157, 78-92

[8] Bai, Jushan, and Pierre Perron (1998) 'Estimating and Testing Linear Models with Multiple Structural Changes.' Econometrica 66, 47-78

[9] Bai, Jushan, and Pierre Perron (2003) 'Computation and Analysis of Multiple Structural Change Models.' Journal of Applied Econometrics 18, 1-22

[10] Basle III (2010) 'Basel III: 'A Global Regulatory Framework for More Resilient Banks and Banking Systems,' Bank for International Settlements Working Series. 
[11] Beaupain, Renaud, and Alain Durré ( 2013) 'Central Bank Reserves and Interbank Market Liquidity in the Euro Area.' Journal of Financial Intermediation 22, 259-284

[12] Bernanke, Ben S. (2013) The Federal Reserve and the Financial Crisis - Lectures. Princeton University Press

[13] Bernanke, Ben S., and Mark Gertler (1989) 'Agency Costs, Net Worth, and Business Fluctuations.' American Economic Review 79, 14-31

[14] Bhamra, Harjoat S., Adlai J. Fisher, Lars-Alexander Kühn (2011) 'Monetary Policy and Corporate Default.' Journal of Monetary Economics 58, 480-494

[15] Bhamra, Harjoat S., Lars-Alexander Kühn., and Ilya A. Strebulaev (2010) 'The Levered Equity Risk Premium and Credit Spreads: A Unified Framework.' Review of Financial Studies 23, 645-703

[16] Buraschi, Andrea, Fabio Trojani, and Andrea Vedolin (2011) 'Economic Uncertainty, Disagreement, and Credit Markets.' Working paper, London School of Economics

[17] Cenesizoglu, Tolga, Badye Essid (2012) 'The Effect of Monetary Policy on Credit Spreads.' Journal of Financial Research 35, 581-613

[18] Chant, John F. (2013) 'Is the Regulation of Financial Institutions Meeting Its Public Policy Objectives?' Mimeo

[19] Chant, John F. (2008) 'The ABCP Crisis in Canada: The Implications for the Regulation of Financial Markets.' Canada Expert Panel on Securities Regulation: http://www.expertpanel.ca/eng/reports/research-studies/the-abcp-crisis-in-canadachant.html

[20] Chen, Gongmeng, Yoon K. Choi, and Yong Zhou (2005) 'Nonparametric Estimation of Structural Change Points in Volatility Models for Time Series.' Journal of Econometrics $126,79-114$

[21] Chen, Hui (2010) 'Macroeconomic Conditions and the Puzzles of Credit Spreads and Capital Structure.' Journal of Finance 65, 2171-2212

[22] Chen, Nai-Fu (1991) 'Financial Investment Opportunities and the Macroeconomy.' Journal of Finance 46, 529-554

[23] Chen, Long, Pierre Collin-Dufresne, and Robert S. Goldstein (2009) 'On the Relation between the Credit Spread Puzzle and the Equity Premium Puzzle.' Review of Financial Studies 22, 3367-3409

[24] Chen, Long, David A. Lesmond, and Jason Wei (2007) 'Corporate Yield Spreads and Bond Liquidity.' Journal of Finance 62, 119-149

[25] Chen, Ren-Raw, Xiaolin Cheng, and Liuren Wu (2011) 'Dynamic Interactions Between Interest-Rate and Credit Risk: Theory and Evidence on the Credit Default Swap Term Structure,' Review of Finance, Advance Access Publication, 1-39

[26] Chiaramonte, Laura, and Barbara Casu (2012) 'The Determinants of Bank CDS Spreads: Evidence from the Financial Crisis.' European Journal of Finance, DOI: 10.1080/1351847X.2011.636832 
[27] Chib, Siddhartha (1998) 'Estimation and Comparison of Multiple Change Point Models.' Journal of Econometrics 86, 221-241

[28] Chun, Albert Lee, and Fan Yu (2013) 'Monolines and the Municipal Bond Market.' Working Paper, Claremont McKenna College

[29] Collin-Dufresne, Pierre, Robert S. Goldstein, and J. Spencer Martin (2001) 'The Determinants of Credit Spread Changes.' Journal of Finance 56, 2177-2208

[30] Cox, John C., Jonathan E. Ingersoll, and Stephen A. Ross, (1985) 'A Theory of the Term Structure of Interest Rates.' Econometrica 53, 385-407

[31] Davis, Richard A., Thomas C.M. Lee, and Gabriel A. Rodriguez-Yam (2008) 'Break Detection for a Class of Nonlinear Time-Series Models.' Journal of Time Series Analysis 29, 834-867

[32] Degryse, Hans, Frank de Jong, Maarten van Ravenswaaij, and Gunther Wuyts (2005) 'Agressive Orders and the Resiliency of a Limit Order Market.' Review of Finance 9, 201-242

[33] Dick-Nielsen, Jens (2009) 'Liquidity Biases in TRACE.' Journal of Fixed Income 19, 43-55

[34] Dick-Nielsen, Jens, Peter Feldhütter, and David Lando (2012) 'Corporate Bond Liquidity Before and After the Onset of the Subprime Crisis.' Journal of Financial Economics 103, 471-492

[35] Dionne, Georges (2013) 'Risk Management: History, Definition and Critique.' Risk Management and Insurance Review, forthcoming. Available at SSRN: http://papers.ssrn.com/sol3/papers.cfm?abstract_id=2231635

[36] Dionne, Georges, Geneviève Gauthier, Khemais Hammami, Mathieu Maurice, and JeanGuy Simonato (2011) 'A Reduced Form Model of Default Spreads with Markov-Switching Macroeconomic Factors.' Journal of Banking and Finance 35, 1984-2000

[37] Dionne, Georges, Khemais Hammami, Geneviève Gauthier, Mathieu Maurice, and JeanGuy Simonato (2010) 'Default Risk in Corporate Yield Spreads.' Financial Management $39,707-731$

[38] Driessen, Joost (2005) 'Is Default Event Risk Priced in Corporate Bonds?' Review of Financial Studies 18, 165-195

[39] Duan, Jin-Chuan, and Jean-Guy Simonato (1998) 'Estimating and Testing Exponential Affine Term Structure Models by Kalman Filters, Review of Quantitative Finance and Accounting 13, 111-135

[40] Duffee, Gregory R. (1998) 'The Relation between Treasury Yields and Corporate Bond Yield Spreads.' Journal of Finance 53, 2225-2241

[41] Duffie, Darrell, and Kenneth J. Singleton (1999) 'Modeling Term Structures of Defaultable Bonds.' Review of Financial Studies 12, 687-720.

[42] Duffie, Darrell, and Kenneth J. Singleton (2003) Credit Risk - Pricing, Measurement, and Management. Princeton Series in Finance 
[43] Ejsing, Jacob, Magdalena Grothe, and Oliver Grothe (2012) 'Liquidity and Credit Risk Premia in Government Bond Yields.' Working paper No 1440, European Central Bank

[44] Elton, Edwin J., Martin J. Gruber, Deepak Agrawal, and Christopher Mann (2001) 'Explaining the Rate Spread on Corporate Bonds.' Journal of Finance 56, 247-277

[45] Ericsson, Jan, and Olivier Renault (2006) 'Liquidity and Credit Risk.' Journal of Finance $61,2219-2250$

[46] Fama, Eugene F., and Kenneth R. French (1989) 'Business Conditions and Expected Returns on Stocks and Bonds.' Journal of Financial Economics 25, 23-49

[47] Feldhütter, Peter, and David Lando (2008) 'Decomposing Swap Spreads.' Journal of Financial Economics 88, 375-405

[48] Foucault, Thierry, Kadan Ohad, and Eugene Kandel (2005) 'Limit Order Book as a Market for Liquidity.' Review of Financial Studies 18, 1171-1217

[49] Giesecke, Kay, Francis A. Longstaff, Stephen Schaefer, and Ilya Strebulaev (2011) 'Corporate Bond Default Risk: A 150-Year Perspective.' Journal of Financial Economics 102, 233-250

[50] Giordani, Paolo, and Robert Kohn (2008) 'Efficient Bayesian Inference for Multiple Change Point and Mixture Innovation Models.' Journal of Business and Economic Statistics 26, 66-77

[51] Gordon, Louis, and Moshe Pollak (1994) 'An Efficient Sequential Nonparametric Scheme for Detecting a Change of Distribution.' Annals of Statistics 22, 763-804

[52] Hackbarth, Dirk, Jianjun Miao, and Erwan Morellec (2006) 'Capital Structure, Credit Risk, and Macroeconomic Conditions.' Journal of Financial Economics 82, 519-550

[53] Han, Song, and Hao Zhou (2008) 'Effect of Liquidity on the Nondefault Component of Corporate Bond Spreads: Evidence from Intraday Transactions Data.' Finance and Economics Discussion Series 2008-40, Federal Reserve System

[54] Hasbrouck, Joel (2009) 'Trading Costs and Returns for U.S. Equities: Estimating Effective Costs from Daily Data.' Journal of Finance 64, 1445-1477

[55] Huang, Jing-Zhi, and Ming Huang (2003) 'How Much of the Corporate-Treasury Yield Spread is Due to Credit Risk?' Working Paper, Pennsylvania State University

[56] Huang, Roger D., and Hans R. Stoll (1996) 'Dealer Versus Auction Markets: A Paired Comparison of Execution Costs on NASDAQ and the NYSE.' Journal of Financial Economics 41, 313-357

[57] Hull, John, Mirela Predescu, and Alan White (2004) 'The Relationship between Credit Default Swap Spreads, Bond Yields, and Credit Rating Announcements.' Journal of Banking and Finance 28, 2789-2811

[58] King, Mervyn (1994) 'Debt Deflation: Theory and Evidence.' European Economic Review $38,419-445$ 
[59] Kiyotaki, Nobuhiro, and John Moore (1997) 'Credit Cycles.' Journal of Political Economy $105,211-248$

[60] Kyle, Albert S. (1985) 'Continuous Auctions and Insider Trading.' Econometrica 53, 13151335

[61] Lando, David (2004) Credit Risk Modeling - Theory and Applications. Princeton University Press

[62] Lando, David, and Torben M. Skodeberg (2002) 'Analyzing Rating Transitions and Rating Drift with Continuous Observations.' Journal of Banking and Finance 26, 423-444

[63] Longstaff, Francis A., Sanjay Mithal, and Eric Neis (2005) 'Corporate Yield Spreads: Default Risk or Liquidity? New Evidence from the Credit Default Swap Market.' Journal of Finance 60, 2213-2253

[64] Lu, Yang K., and Pierre Perron (2010) 'Modeling and Forecasting Stock Return Volatility Using a Random Level Shift Model.' Journal of Empirical Finance 17, 138-156

[65] Maalaoui Chun, Olfa, Georges Dionne, and Pascal François (2010) 'Credit Spread Changes within Switching Regimes.' Working paper 09-01, Canada Research Chair in Risk Management, HEC Montreal. Available at SSRN: http://papers.ssrn.com/sol3/papers.cfm?abstract_id=1341870

[66] Maalaoui Chun, Olfa, Georges Dionne, and Pascal François (2013) 'Detecting Regime Shifts in Credit Spreads.' Forthcoming in Journal of Financial and Quantitative Analysis. Available at SSRN: http://ssrn.com/abstract=1341870

[67] Maheu, John H., and Thomas H. McCurdy (2009) 'How Useful are Historical Data for Forecasting the Long-Run Equity Return Distribution?' Journal of Business and Economic Statistics 27, 95-112

[68] Ng, Serena (2013) 'Predicting Recessions.' State of the Art Lecture, Canadian Economic Association Meetings, Montreal, June 2013

[69] Perron, Pierre, and Zhongjun Qu (2006) 'Estimating Restricted Structural Change Models.' Journal of Econometrics 134, 373-399

[70] Pesaran, M. Hashem, Davide Pettenuzzo, and Allan Timmermann (2006) 'Forecasting Time Series Subject to Multiple Structural Breaks.' Review of Economic Studies 73, 10571084

[71] Roll, Richard (1984) 'A Simple Implicit Measure of the Effective Bid-ask Spread in an Efficient Market.' Journal of Finance 39, 1127-1139

[72] Saunders, Anthony, and Linda Allen (2010) Credit Risk - Measurement In and Out of the Financial Crisis. Hoboken, NJ: John Wiley \& Sons, Inc.

[73] Stoll, Hans R. (2000) 'Presidential Address: Friction.' Journal of Finance 55, 1479-1514

[74] Stulz, René (2010) 'Credit Default Swaps and the Credit Crisis,' Journal of Economic Perspectives 24, 73-92 
[75] Wuyts, Gunther (2011) 'The Impact of Agressive Orders in an Orderdriven Market: A Simulation Approach.' European Journal of Finance, DOI: 10.1080/1351847X.2011.601631

[76] Zorn, Lorie, Carolyn Wilkins, and Walter Engert (2009) 'Bank of Canada Liquidity Actions in Response to the Financial Market Turmoil,' Bank of Canada Review, Autumn, $3-22$. 
Figure 1: Dynamics of average credit spreads and major financial events during 2007-2009.

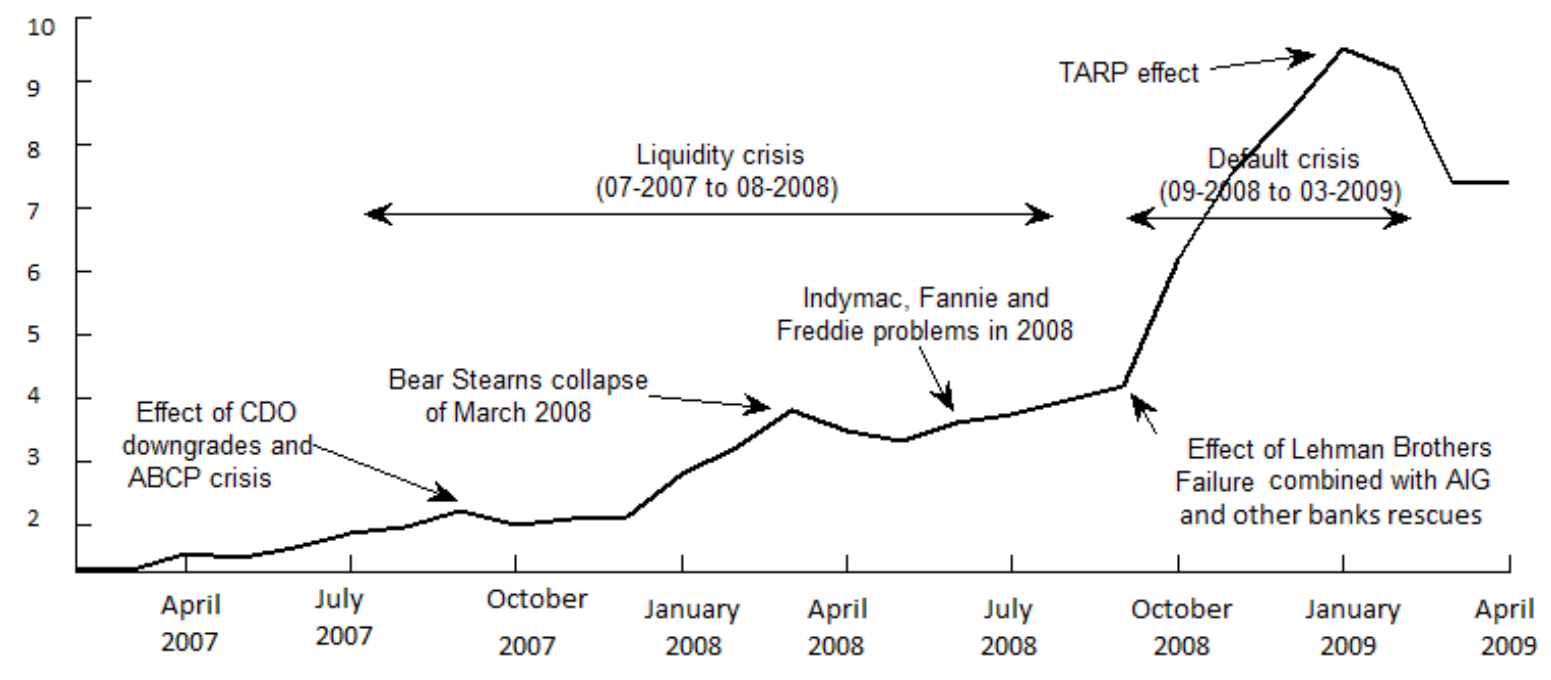


Figure 2: The dynamics of credit spreads (2002-2012).

We plot the aggregate credit spread obtained as an average of credit spreads of all the firms in our sample. We obtain the credit spread for each firm using the Nelson Siegel algorithm fitting the data for different maturities. The shaded region in Panel A represents the 2007 period of NBER recession (December 2007 to June 2009) and, in Panel B it represents the 2007 period of financial crisis (July 2007 to Mars 2009). The plot spans from January 2002 to December 2012.

Panel A: The dynamics of credit spreads during the 2007 NBER recession

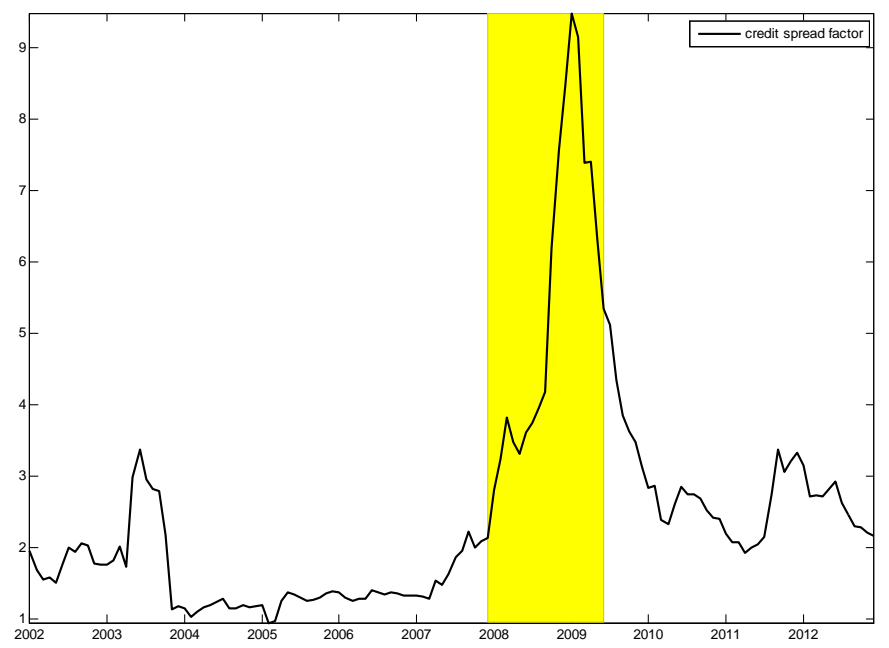

Panel B: The dynamics of credit spreads during the 2007 financial crisis

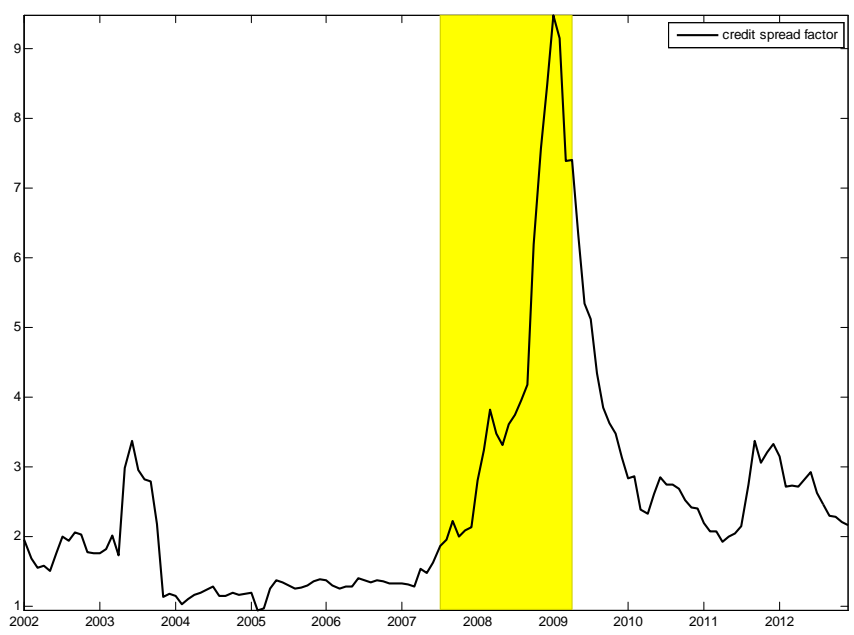


Figure 3: The dynamics of the credit spread factor.

We plot the credit spread factor obtained as an average of credit spreads of all the firms in our sample along with its detected level regimes. We illustrate the dynamics of the credit spread factor during the 2007 NBER recession in Panel A and during the 2007 financial crisis in Panel B. We obtain the credit spread for each firm using the Nelson Siegel algorithm fitting the data for different maturities. The detected regimes are significant at least at the $95 \%$ confidence level $(\alpha=0.05)$. We use an initial cut-off length of six data points $(m=6)$ and an Huber parameter of two $(h=2)$. We prewhiten the data before applying the regime detection technique. The shaded regions represents the 2007 period of NBER recession (December 2007 to June 2009) and the 2007 period of financial crisis (July 2007 to Mars 2009). The plot spans from January 2002 to December 2012.

Panel A: Credit spread factor during the 2007 NBER recession

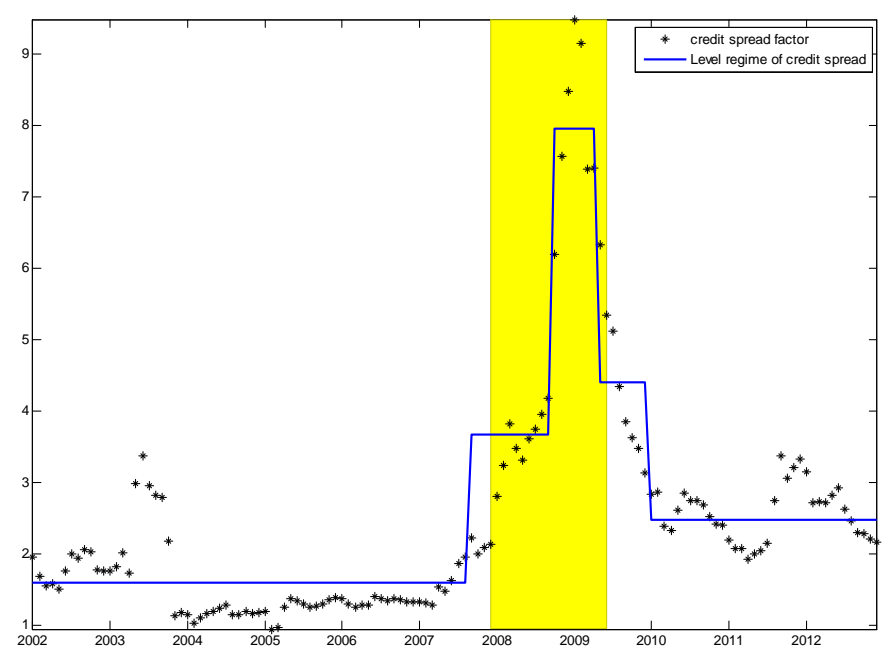

Panel B: Credit spread factor during the 2007 financial crisis

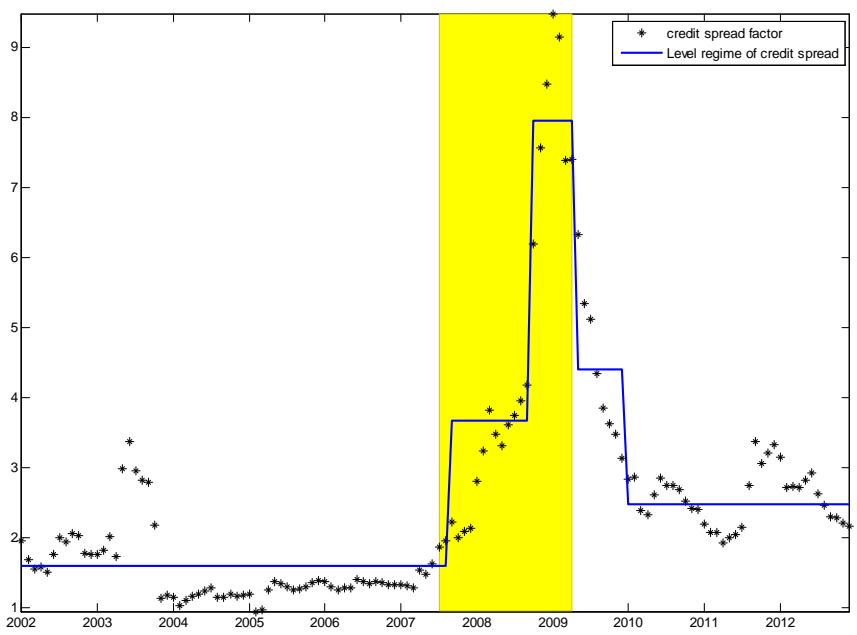


Figure 4: The CDS, the implied intensity of default (Q-intensity), and the NBER recession.
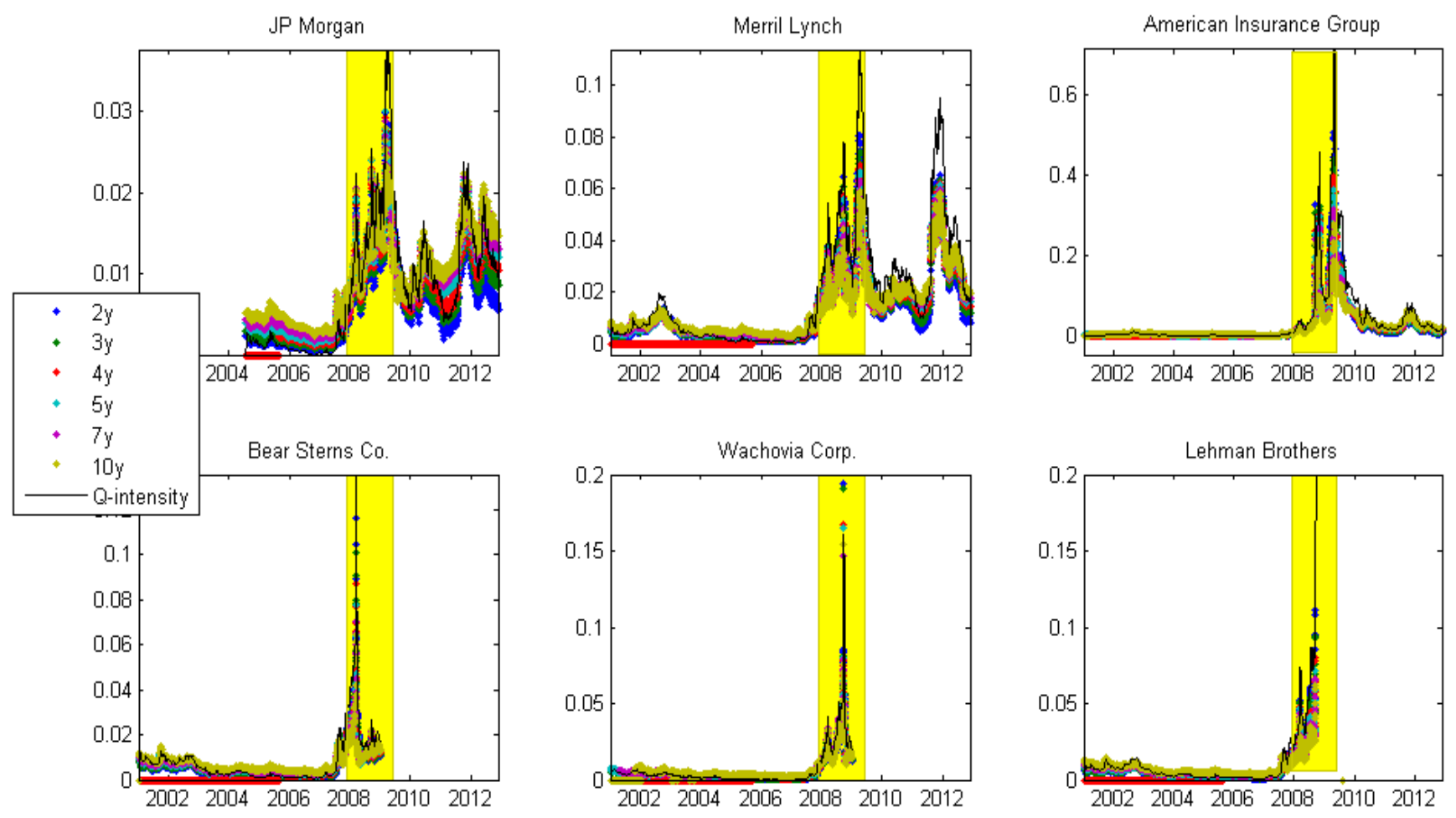


\section{Figure 5: The dynamics of the default factor.}

We plot the default factor obtained as an average of the Q-intensity of default of all the firms in our sample along with its detected level regimes. We illustrate the dynamics of the default factor during the 2007 NBER recession in Panel A and during the 2007 financial crisis in Panel B. We obtain the Q-intensity for each firm by fitting the CDS data for different maturities (six months to ten years for each issuer in the dataset) into the Longstall, Mithal, and Neis (2006) setting. The detected regime is significant at least at the 95\% confidence level $(\alpha=0.05)$. We use an initial cut-off length of six data points $(m=6)$ and an Huber parameter of two $(h=2)$. We prewhiten the data before applying the regime detection technique. The shaded regions represents the 2007 period of NBER recession (December 2007 to June 2009) and the 2007 period of financial crisis (July 2007 to Mars 2009). The plot spans from January 2001 to December 2012.

Panel A: Default factor during the 2007 NBER recession

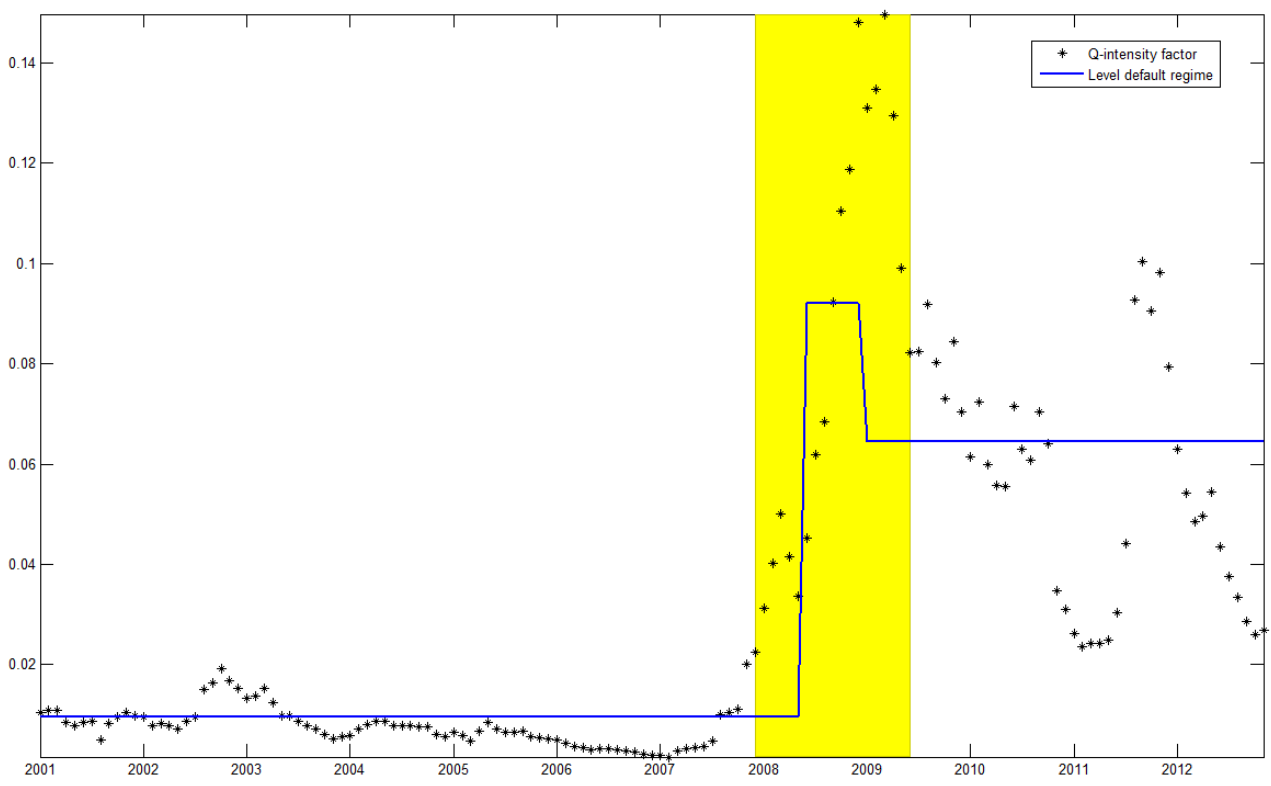

Panel B: Default factor during the 2007 financial crisis

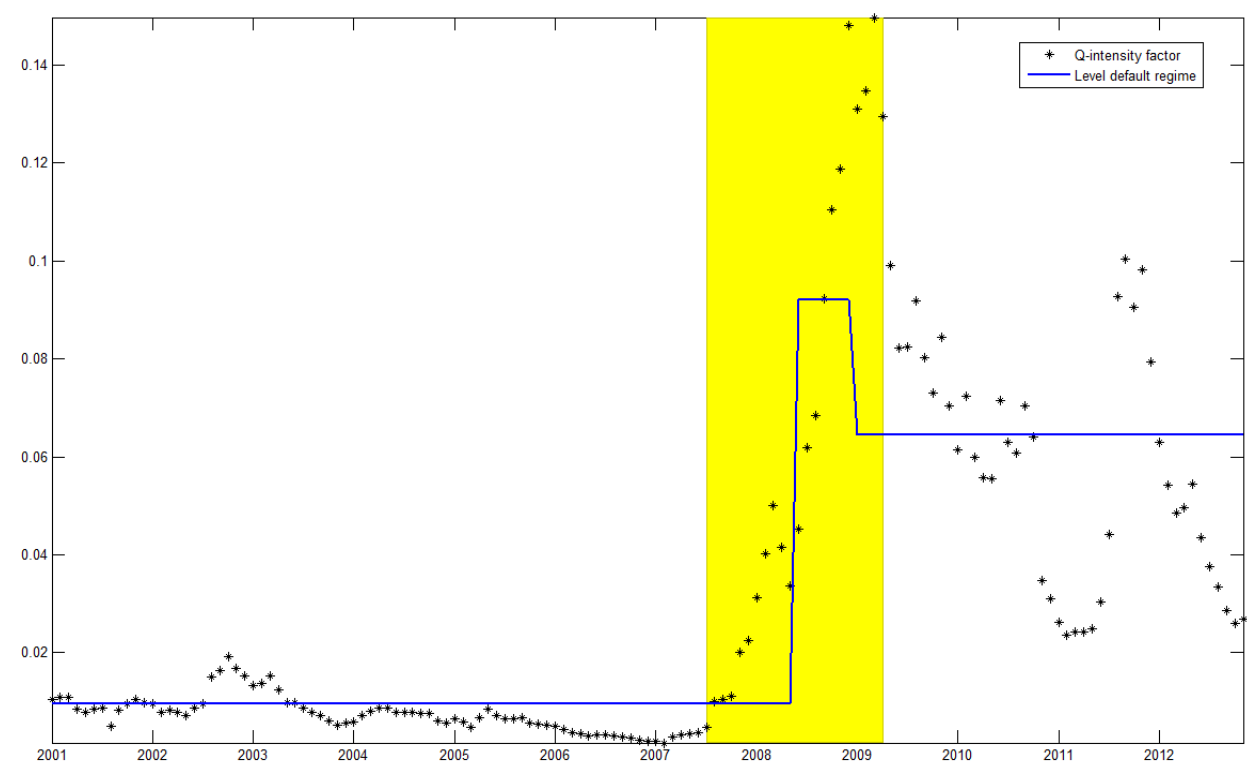


Figure 6: The dynamics of the eight liquidity variables.

We plot the time series of the eight liquidity variables averaged across the firms included in our sample. Details on the construction of these variables are reported in Section III. We illustrate the dynamics of the default factor during the 2007 NBER recession in Panel A and during the 2007 financial crisis in Panel B. The shaded regions represents the 2007 period of NBER recession (December 2007 to June 2009) and the 2007 period of financial crisis (July 2007 to Mars 2009). The plot spans from July 2002 to December 2012.

Panel A: The dynamics of liquidity variables during the 2007 NBER recession
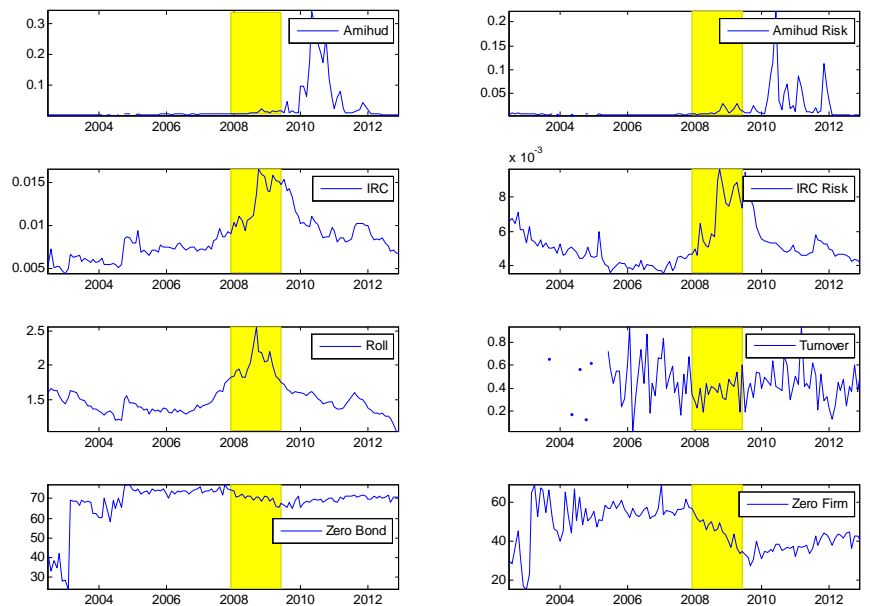

Panel B: The dynamics of liquidity variables during the 2007 financial crisis
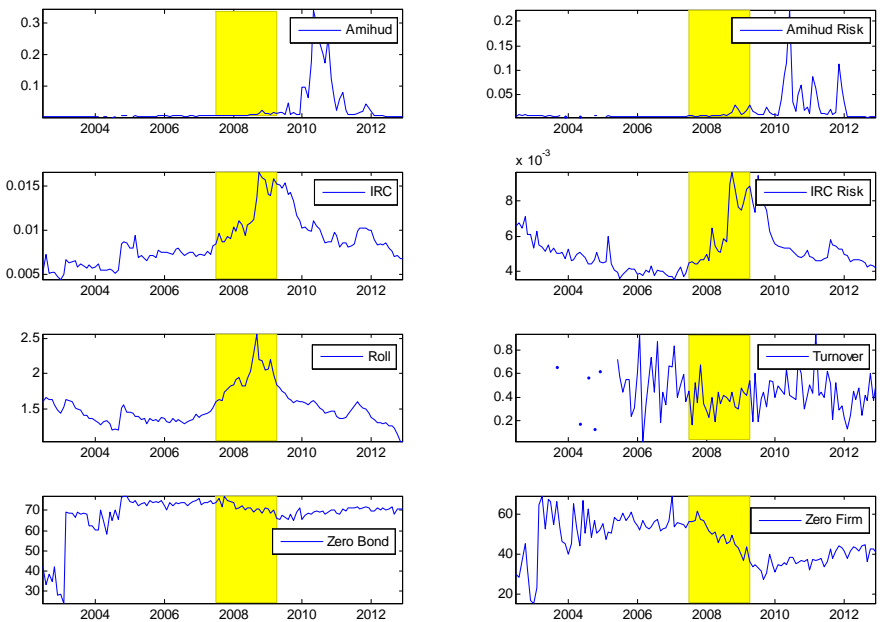
Figure 7: The dynamics of the liquidity factor.

We plot the liquidity factor along with its detected level regimes. We illustrate the dynamics of the liquidity factor during the 2007 NBER recession in Panel A and during the 2007 financial crisis in Panel B. The liquidity factor is obtained as the average of the URC, the URC risk, and the Roll measures, which represent the first principal component of the eight liquidity factors considered in this study. The detected regimes are significant at least at the $95 \%$ confidence level $(\alpha=0.05)$. We use an initial cut-off length of six data points $(m=6)$ and an Huber parameter of two $(h=2)$. We prewhiten the data before applying the regime detection technique. The shaded regions represents the 2007 period of NBER recession (December 2007 to June 2009) and the 2007 period of financial crisis (July 2007 to Mars 2009). The plot spans from July 2002 to December 2012.

Panel A: Liquidity factor during the 2007 NBER recession

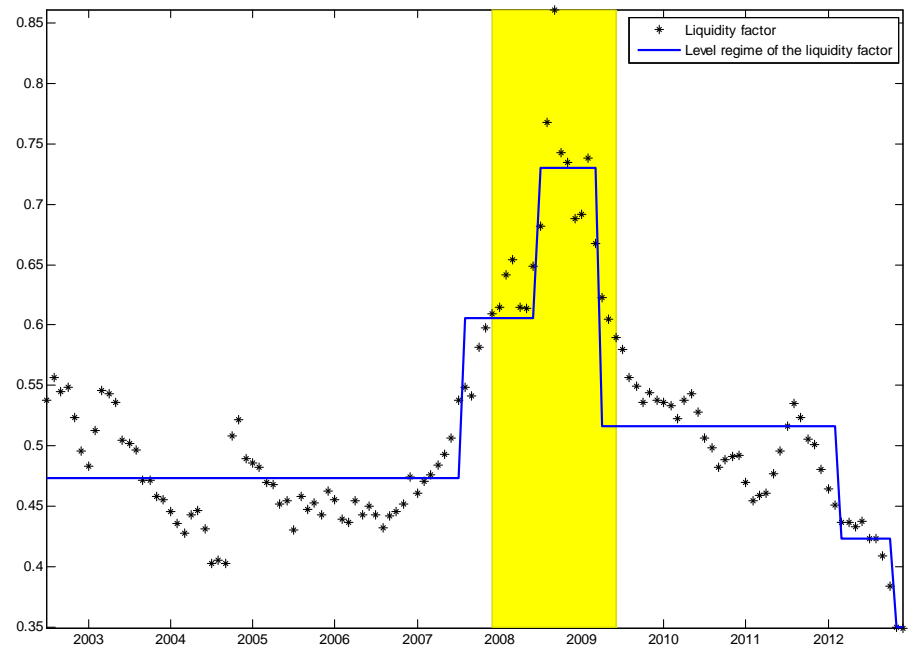

Panel B: Liquidity factor during the 2007 financial crisis

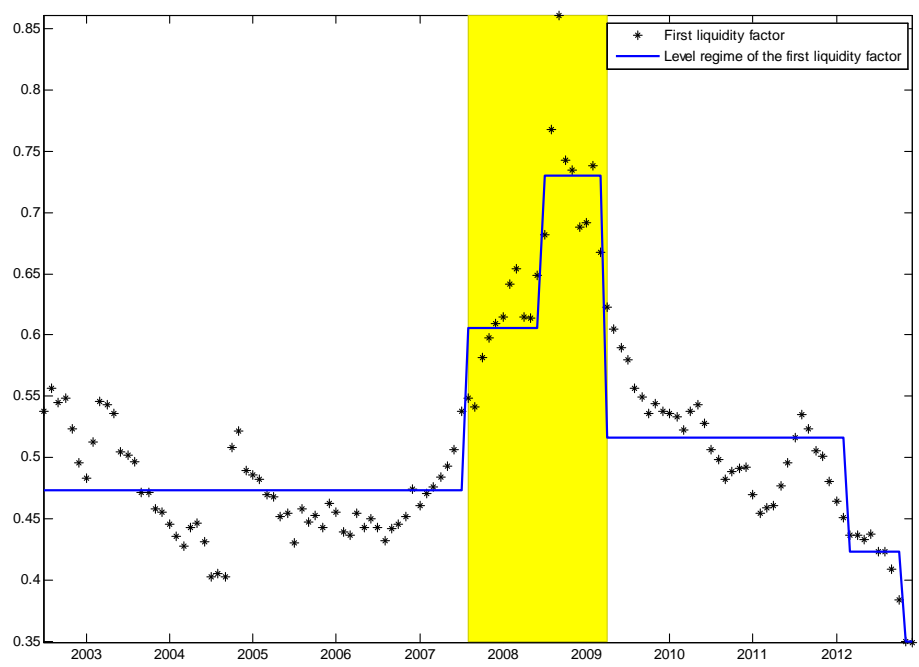


Table 1: Summary Statistics for Changing Points in Level Regimes.

We report the results of the regime shift detection technique applied to the level of 1) the (average) credit spreads (Panel A), 2) the default factor (Panel B), and 3) the liquidity factor (Panel C). The initial cut-off length is 6 months, the Huber parameter is 2, and all detected regimes are statistically significant at the $95 \%$ confidence level or higher. The sign of the Regime Shift Index (RSI sign) provides the direction of detected shifts. Regime means are expressed in percentages and regime lengths in months.

\begin{tabular}{ccccccc}
\hline Shift & Mean of & Length of & Date of & Mean of & Length of & RSI \\
No. & Current & Current & Shift & New & New & Sign \\
& Regime & Regime & Point & Regime & Regime & \\
\hline
\end{tabular}

Panel A : Shifts in credit spreads (April 2002 to December 2012)

$\begin{array}{ccclccr}1 & 1.599 & 68 & \text { Sep-07 } & 3.665 & 13 & + \\ 2 & 3.665 & 13 & \text { Oct-08 } & 7.955 & 7 & + \\ 3 & 7.955 & 7 & \text { May-09 } & 4.401 & 8 & - \\ 4 & 4.401 & 8 & \text { Jan-10 } & 2.477 & 36 & -\end{array}$

Panel B : Shifts in the default factor (January 2001 to December 2012)

$\begin{array}{ccccccc}1 & 0.010 & 89 & \text { Jun-08 } & 0.092 & 7 & + \\ 2 & 0.092 & 7 & \text { Jan-09 } & 0.064 & 48 & -\end{array}$

Panel C : Shifts in the liquidity factor (July 2002 to December 2012)

\begin{tabular}{ccclccc}
1 & 0.473 & 61 & Jul-07 & 0.606 & 11 & + \\
2 & 0.606 & 11 & Jun-08 & 0.730 & 9 & + \\
3 & 0.730 & 9 & Mar-09 & 0.516 & 35 & - \\
4 & 0.516 & 35 & Feb-12 & 0.423 & 10 & - \\
\hline
\end{tabular}

Table 2: Summary statistics of the CDS data.

The table reports summary statistics for the daily CDS premiums $\left(s_{i}\right)$ the recovery rate $\left(1-w_{i}\right)$, and the annualized credit spread data. The data for CDS is from January 2001 to December 2012 and the data for credit spreads is from July 2002 to December 2012.

\begin{tabular}{|c|c|c|c|c|c|c|c|c|c|c|}
\hline & $6 \mathrm{~m}$ & $1 y$ & $2 y$ & $3 y$ & $4 y$ & $5 y$ & $7 y$ & $10 y$ & $\begin{array}{c}\text { Recovery } \\
\left(1-w_{i}\right)\end{array}$ & $\mathrm{CS}$ \\
\hline 99th & 0.33476 & 0.26705 & 0.24553 & 0.22146 & 0.26097 & 0.19777 & 0.17749 & 0.15909 & 0.50000 & 9.21265 \\
\hline 95th & 0.08162 & 0.06723 & 0.06850 & 0.06630 & 0.09618 & 0.06614 & 0.06518 & 0.06400 & 0.42222 & 6.30878 \\
\hline 75 th & 0.01086 & 0.01084 & 0.01260 & 0.01433 & 0.02272 & 0.01704 & 0.01862 & 0.01948 & 0.40000 & 2.85990 \\
\hline 50 th & 0.00293 & 0.00354 & 0.00451 & 0.00573 & 0.01020 & 0.00777 & 0.00852 & 0.00950 & 0.40000 & 2.05970 \\
\hline 25 th & 0.00084 & 0.00121 & 0.00179 & 0.00245 & 0.00367 & 0.00368 & 0.00432 & 0.00515 & 0.38750 & 1.35010 \\
\hline 5 th & 0.00036 & 0.00053 & 0.00084 & 0.00117 & 0.00143 & 0.00186 & 0.00229 & 0.00286 & 0.30000 & 1.14698 \\
\hline $1 \mathrm{st}$ & 0.00021 & 0.00034 & 0.00052 & 0.00076 & 0.00089 & 0.00124 & 0.00161 & 0.00207 & 0.24545 & 0.96915 \\
\hline
\end{tabular}


Table 3: Summary statistics of the eight liquidity variables.

The table reports summary statistics for the eigth liquidity measures considered in this study. The data spans from July 2002 to December 2012.

\begin{tabular}{lcccccccc}
\hline & Amihud & IRC & $\begin{array}{c}\text { Amihud } \\
\text { Risk }\end{array}$ & $\begin{array}{c}\text { IRC } \\
\text { Risk }\end{array}$ & Roll & Turnover & $\begin{array}{c}\text { Bond } \\
\text { zero }\end{array}$ & $\begin{array}{c}\text { Firm } \\
\text { zero }\end{array}$ \\
\hline 99th & 0.09347 & 0.05116 & 0.07403 & 0.02830 & 4.15054 & 0.96000 & 95.65217 & 95.65217 \\
95th & 0.03117 & 0.02705 & 0.02628 & 0.01548 & 3.25524 & 0.88667 & 95.45455 & 95.23810 \\
75th & 0.00916 & 0.01216 & 0.00603 & 0.00733 & 2.08110 & 0.66667 & 95.00000 & 85.00000 \\
50th & 0.00384 & 0.00612 & 0.00171 & 0.00397 & 1.35564 & 0.40000 & 86.36364 & 50.00000 \\
25th & 0.00120 & 0.00287 & 0.00000 & 0.00050 & 0.83966 & 0.20000 & 54.54545 & 4.54545 \\
5th & 0.00001 & 0.00032 & 0.00000 & 0.00000 & 0.39911 & 0.11333 & 0.00000 & 0.00000 \\
1st & 0.00000 & 0.00000 & 0.00000 & 0.00000 & 0.18403 & 0.06000 & 0.00000 & 0.00000 \\
\hline
\end{tabular}

Table 4: Correlation between on the eight liquidity variables.

The table reports the correlation coefficients between the eight liquidity variables.

\begin{tabular}{|c|c|c|c|c|c|c|c|c|}
\hline & Amihud & IRC & Roll & Zero Firm & Zero Bond & Turnover & Amihud Risk & IRC Risk \\
\hline Amihud & 1 & & & & & & & \\
\hline IRC & 0.0846 & 1 & & & & & & \\
\hline Roll & -0.0095 & 0.7712 & 1 & & & & & \\
\hline Zero Firm & -0.2779 & -0.5255 & -0.0808 & 1 & & & & \\
\hline Zero Bond & -0.2798 & -0.4209 & -0.1686 & 0.5826 & 1 & & & \\
\hline Turnover & 0.1208 & -0.1791 & -0.1577 & -0.0027 & 0.1018 & 1 & & \\
\hline Amihud Risk & 0.7377 & 0.1443 & 0.0251 & -0.2541 & -0.2204 & 0.0604 & 1 & \\
\hline IRC Risk & 0.0278 & 0.9471 & 0.7328 & -0.5662 & -0.531 & -0.1708 & 0.0938 & 1 \\
\hline
\end{tabular}


Table 5: Principal component analysis of the liquidity variables.

The table reports the results for the principal component analysis of the eigth liquidity variables considered in our study. Panel A reports the eigenvalues of the eight components (1PC to $8 \mathrm{PC}$ ) and Panel $\mathrm{B}$ reports the corresponding eigenvectors.

Panel A: Eigenvalues of the eight principal components

\begin{tabular}{lcccc}
\multicolumn{4}{c}{ Panel A: Eigenvalues of the eight principal components } \\
\hline PCs & Eigenvalue & Difference & Proportion & Cum. \% explained \\
& & & & \\
\hline 1PC & 3.3470 & 1.4709 & 0.4184 & 0.4184 \\
2PC & 1.8761 & 0.8845 & 0.2345 & 0.6529 \\
3PC & 0.9916 & 0.0602 & 0.1239 & 0.7768 \\
4PC & 0.9314 & 0.4887 & 0.1164 & 0.8933 \\
5PC & 0.4427 & 0.1855 & 0.0553 & 0.9486 \\
6PC & 0.2572 & 0.1421 & 0.0321 & 0.9807 \\
7PC & 0.1151 & 0.0762 & 0.0144 & 0.9951 \\
8PC & 0.0390 &. & 0.0049 & 1.0000 \\
& & & & \\
\hline
\end{tabular}

Panel B: Eigenvectors of the eight principal components

\begin{tabular}{|c|c|c|c|c|c|c|c|c|}
\hline & $1 \mathrm{PC}$ & $2 \mathrm{PC}$ & $3 \mathrm{PC}$ & $4 \mathrm{PC}$ & $5 \mathrm{PC}$ & $6 \mathrm{PC}$ & $7 \mathrm{PC}$ & $8 \mathrm{PC}$ \\
\hline Amihud & 0.1623 & 0.6102 & 0.2803 & -0.0839 & -0.1056 & -0.683 & 0.1785 & 0.0786 \\
\hline IRC & 0.5037 & -0.1887 & 0.1357 & 0.1064 & 0.1837 & 0.0047 & 0.4456 & -0.6698 \\
\hline Amihud Risk & 0.1791 & 0.5701 & 0.376 & -0.1321 & 0.1392 & 0.6735 & -0.1054 & 0.002 \\
\hline IRC Risk & 0.5105 & -0.201 & -0.0016 & 0.1075 & 0.0513 & 0.1034 & 0.3825 & 0.7265 \\
\hline Roll & 0.3725 & -0.3161 & 0.5047 & 0.1502 & -0.222 & -0.1388 & -0.6446 & 0.0046 \\
\hline Turnover & -0.1031 & 0.2389 & -0.0557 & 0.9534 & -0.118 & 0.072 & 0.0268 & -0.0187 \\
\hline Zero Bond & -0.3671 & -0.171 & 0.4806 & 0.1344 & 0.7389 & -0.1437 & 0.0568 & 0.1303 \\
\hline Zero Firm & -0.3783 & -0.2011 & 0.5223 & -0.0544 & -0.5691 & 0.1549 & 0.439 & 0.0064 \\
\hline
\end{tabular}

